Rx Price Watch Report

\title{
Trends in Retail Prices of Specialty Prescription Drugs Widely Used by Older Americans: 2017 Year-End Update
}

Stephen W. Schondelmeyer

PRIME Institute, University of Minnesota

\section{Leigh Purvis}

AARP Public Policy Institute

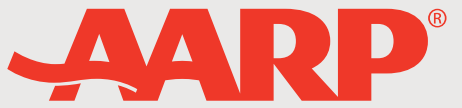

Real Possibilities 



\section{Table of Contents}

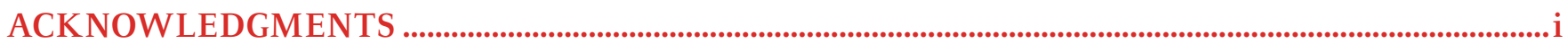

EXECUTIVE SUMMARY ....................................................................................................................................................... 1

INTRODUCTION

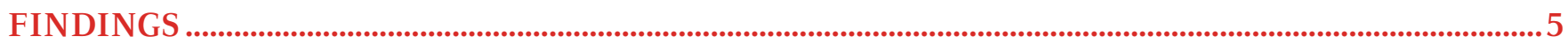

I. Specialty Price Trends for Most Widely Used Prescription Drugs...................................................5

II. Annual Trends in Price Changes for Most Widely Used Specialty Prescription Drugs

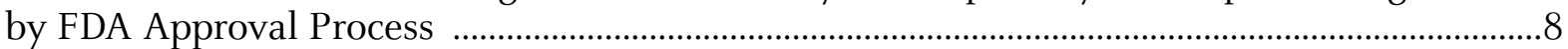

III. Twelve-Year Cumulative Retail Price Changes for Most Widely Used Specialty Prescription Drugs, 2006-17 ..................................................................................................... 10

IV. More than 8 out of 10 Widely Used Specialty Drugs Increased in Price Faster than General Inflation in 2017 .

V. Retail Price Changes for Most Widely Used Specialty Prescription Drugs by Manufacturer...........................................................................................................................................

VI. Retail Price Changes for Most Widely Used Specialty Prescription Drugs by Therapeutic Category …................................................................................................................

CONCLUDING OBSERVATIONS .............................................................................................................................. 16

APPENDIX A. DETAILED METHODOLOGY AND DESCRIPTION OF RETAIL PRICE DATA ....17

APPENDIX B. THERAPEUTIC CATEGORY ACRONYMS .............................................................................25 


\section{Figures}

Figure 1. Average Annual Specialty Drug Price Increase Is over Three Times Higher than General Inflation in 2017

Figure 2. Rolling Average and Point-to-Point Changes in Retail Prices for Most Widely Used Specialty Prescription Drugs Greatly Exceeded Inflation from 2007 to 2017

Figure 3. The Average Annual Price of Specialty Drugs Almost Tripled between 2006 and 2017

Figure 4. The Average Annual Retail Price of Therapy for Specialty Drugs Is Substantially Higher than the Average Annual Retail Price of Therapy for Brand Name and Generic Drugs in 2017 .

Figure 5. The Average Annual Cost of Specialty Drugs Would Be Nearly \$50,000 Lower if Retail Price Changes Were Limited to General Inflation

Figure 6. Average Retail Prices Are Higher among BLA-Approved Specialty Prescription Drugs ..... 10

Figure 7. The Average Annual Cost of Therapy Increased by More than 240 Percent for Widely Used BLA-Approved Specialty Prescription Drugs between 2006 and 2017 .

Figure 8. Retail Prices Increased for More than 8o Percent of Most Widely Used Specialty Drugs in 2017

Figure 9. Retail Prices for Three Widely Used Specialty Drugs Increased by More than 20 Percent in 2017.

Figure 10. Retail Prices for 10 Widely Used Specialty Prescription Drugs Decreased in 2017 ...14

Figure 11. Twenty-Five of 30 Drug Manufacturers Had Retail Price Increases That Exceeded the Rate of General Inflation in 2017

Figure 12. All but Two Therapeutic Categories for Specialty Drugs Had Retail Price Increases That Exceeded the Rate of General Inflation in 2017. 


\section{Executive Summary}

Retail prices for widely used specialty prescription drugs increased substantially more than general inflation in every year from 2006 to 2017. Between 2016 and 2017, retail prices for 97 specialty prescription drugs widely used by older Americans, including Medicare beneficiaries, increased by an average of 7.0 percent. In contrast, the general inflation rate was 2.1 percent over the same period.

Specialty drugs treat conditions that often affect older populations, such as cancer, rheumatoid arthritis, and multiple sclerosis. While there is no set definition for specialty drugs, the term generally includes drugs that are used to treat complex and chronic conditions; that require special administration and handling; or that require patient care management. Another notable characteristic is that they are among the most expensive drugs on the market, with prices that can reach hundreds of thousands of dollars per year.

Increases in the retail price of specialty prescription drugs have a corresponding impact on the cost of drug therapy for the individual and for all other payers. In 2017, the average annual retail cost of prescription drug therapy for a single specialty drug, based on the market basket used in this study, was $\$ 78,781$ per year. This average annual cost was almost $\$ 20,000$ more than the median US household income $(\$ 60,336)$. The annual specialty drug cost was also more than three times the median income for Medicare beneficiaries $(\$ 26,200)$ and over four-and-a-half times higher than the average Social Security retirement benefit $(\$ 16,848)$.

Notably, the average annual cost for one specialty medication used on a chronic basis would have been $\$ 29,843$ in 2017-almost \$50,000 lower-if the retail price changes for these products had been limited to general inflation between 2006 and 2017.

If recent specialty drug price trends continue unabated, an increasing number of vulnerable Americans will be unable to afford necessary specialty medications. Such developments will lead to poorer health outcomes and higher health care costs in the future.

\section{OVERVIEW OF FINDINGS}

- In 2017, retail prices for 97 widely used specialty prescription drugs increased by 7.0 percent. This average annual increase was lower than the specialty drug price increases observed during the prior decade (i.e., 2008 to 2017), which ranged from 7.1 percent to 9.7 percent.

- Specialty drug prices increased more than three times faster than general inflation in 2017 (7.0 percent v. 2.1 percent).

- The average annual cost for a single specialty medication used on a chronic basis was almost $\$ 79,000$ in 2017.

- The average annual cost for one specialty medication used on a chronic basis would have been $\$ 29,843$ in 2017-almost \$50,000 lower - if the retail price changes for these products had been limited to general inflation between 2006 and 2017.

- In 2017, the average annual price of therapy for specialty prescription drugs was almost 12 times higher than the average annual price of therapy for brand name prescription drugs ( $\$ 78,781$ v. $\$ 6,798$, respectively) and over 215 times higher than the average annual price of therapy for generic prescription drugs $(\$ 78,781$ v. $\$ 365$, respectively).

- Retail prices for 27 chronic use specialty drugs that have been on the market since the beginning of the study (i.e., between January 2006 and December 2017) increased cumulatively by an average of 226.4 percent over 12 years. In contrast, general inflation in the US economy rose 25.1 percent during the same 12-year period.

- In 2017, 82 percent (80 of 97) of the widely used specialty prescription drug products in the study's market basket had retail price 
increases that met or exceeded the rate of general economic inflation.

- Retail prices for 83 percent (25 of 30 ) of drug manufacturers with at least one specialty drug product in the study's market basket increased faster than the rate of general inflation (2.1 percent) in 2017.

- Three drug manufacturers had average annual price increases for their specialty drugs of 15 percent or more during 2017more than seven times the rate of general inflation in 2017.

- All but 2 of the 21 therapeutic categories of specialty drug products had average annual retail price increases of 5.0 percent of greater-more than twice the rate of general inflation in 2017.

\section{SPECIALTY PRESCRIPTION DRUG PRICES AND PRICE INCREASES AFFECT ALL AMERICANS}

Until recently, relatively few patients used specialty drugs. However, there are strong indications that a much larger share of the population will use specialty prescription drugs in the future. This report shows that average annual increases in the retail prices of widely used specialty prescription drugs have consistently exceeded the general inflation rate. In addition, the annual retail price associated with widely used specialty drug products now far outstrips what many Americans earn in a given year.
High prescription drug prices and price increases translate into higher out-of-pocket costs, especially for consumers who pay a percentage of drug costs (coinsurance) rather than a fixed dollar amount (copayment). Higher prices can also be passed along to consumers in the form of higher cost sharing, deductibles, and premiums.

Drug prices also affect taxpayer-funded programs like Medicare and Medicaid. For example, the Medicare Payment Advisory Commission recently noted that high drug prices and price increases are driving Medicare prescription drug spending growth. Higher government spending driven by large price increases will affect all Americans in the form of higher taxes, cuts to public programs, or both.

Policy makers interested in slowing prescription drug price increases should focus on changes that produce long-term, sustainable effects. While policy options should encourage meaningful pharmaceutical innovation, such options should be balanced with the need for improved health and the financial security of consumers and taxpayerfunded programs like Medicare and Medicaid.

This report is the latest in the AARP Public Policy Institute's Rx Price Watch series. Separate reports analyze price changes for widely used brand name and generic drug products. The series also analyzes the price changes for an overall market basket (i.e., brand name, generic, and specialty drug products combined) to reflect the overall market impact of drug price changes. 
AARP's Public Policy Institute finds that average retail price increases for specialty prescription drugs widely used by older Americans, including Medicare beneficiaries, far outstripped the price increases for other consumer goods and services between 2006 and 2017. Specialty drug prices have regularly increased much faster than general inflation over the past 14 years - the entire period since the beginning of our report series on prescription drug prices in 2004. ${ }^{1}$ Between 2016 and 2017, the average annual increase in retail prices ${ }^{2}$ for 97 specialty prescription drugs (some are brand name and some are generic) widely used by older Americans was 7.0 percent. In contrast, the rate of general inflation in the US economy was 2.1 percent in 2017.

Previous Rx Price Watch reports found that retail prices for brand name traditional (nonspecialty) drugs widely used by older Americans experienced an 8.4 percent increase in 2017, and retail prices for traditional (nonspecialty) generic drugs widely used by older Americans experienced a 9.3 percent decrease. ${ }^{3}$

Specialty drugs have never been precisely and consistently defined but generally include drugs that are used to treat complex and chronic conditions; that require special administration and handling; or that require patient care management. The definition of specialty prescription drugs used throughout this report is a prescription drug that has one or more of the following characteristics: is administered by injection; has a total average prescription cost greater than \$1,000 per prescription; has a total average cost per day of therapy greater than $\$ 33$ per day; or is in a therapeutic class in which several other drugs in the class meet one or more of the previous criteria (e.g., HIV drugs).

One of the most notable characteristics of specialty drugs is their cost; specialty drugs are among the most expensive drugs on the market, with prices that can reach hundreds of thousands of dollars per year. ${ }^{4}$ Expenditures for this group of specialty

1 The AARP Public Policy Institute in its Rx Price Watch series provides reports with separate analyses of the price changes for three different segments of the pharmaceutical market: brand name, generic, and specialty drug products. These three market baskets are important because a different mix of drug manufacturers typically makes the drug products in each segment and the drug products are subject to unique market dynamics, pricing, and related behaviors. In addition, the $R x$ Price Watch series also reports the price change for an overall market basket (i.e., brand name, generic, and specialty drug products combined) to reflect the overall market impact of drug price changes. Some critics have argued that the brand name price index report alone overstates the effect of drug price changes on the overall prescription drug market. Those critics argue that an overall measure should include the effect of generic prescription drug price competition and the impact of generic substitution. This is precisely why the AARP Rx Price Watch series of reports also provides an overall market basket (including brand name, generic, and specialty drug products) to examine the price change impact for the overall prescription drug market. While this overall perspective is useful for those interested in understanding the industrial economics of the entire prescription drug market, consumers have proved to be considerably more interested in the price trend for the specific products that they are taking as an individual rather than all drug products on the market. In addition, separate analyses of the different market segments (i.e., brand name, generic, and specialty drug products) is important because they represent very unique and distinct segments in the prescription drug market and they provide an indication of policy changes that may be warranted in the various market segments. Previous reports from this series are available on the AARP website at http://www.aarp.org/health/medicare-insurance/info-04-2009/rx watchdog.html and http://www.aarp.org/rxpricewatch.

2 The retail prices used in this report are derived from Truven Health's MarketScan ${ }^{\circledR}$ Commercial Database and MarketScan ${ }^{\circledR}$ Medicare Supplemental Database (Truven Health MarketScan ${ }^{\circledR}$ Research Databases). The prices reflect the total price for a specific prescription that a pharmacy benefit manager (PBM) bills to a specific health plan for consumers enrolled in employer-sponsored or government-sponsored (i.e., Medicare or Medicaid) health plans and not simply the out-of-pocket cost (such as the copay) that a consumer would pay at the pharmacy. These amounts may or may not reflect what the PBM paid the pharmacy or the usual and customary price that a pharmacy would charge a cash-pay consumer for the same prescription.

3 Stephen W. Schondelmeyer and Leigh Purvis, "Rx Price Watch Report: Trends in Retail Prices of Brand Name Prescription Drugs Widely Used by Older Americans, 2017 Year-End Update,” AARP Public Policy Institute, Washington, DC, September 2018; and Stephen W. Schondelmeyer and Leigh Purvis, "Rx Price Watch Report: Trends in Retail Prices of Generic Prescription Drugs Widely Used by Older Americans, 2017 Year-End Update," AARP Public Policy Institute, Washington, DC, April 2019, http://www.aarp.org/rxpricewatch. 
drug products are widely expected to be the fastestgrowing sector of pharmaceuticals in the future. ${ }^{5}$ The impact of this shift is already evident in Medicare Part D spending on specialty drugs, which increased from less than $\$ 9$ billion in 2010 to nearly $\$ 33$ billion in $2015 .{ }^{6}$

Until recently, relatively few patients used specialty drugs. However, the US population is steadily aging and older adults typically use more specialty medications than younger populations. ${ }^{7}$ In addition, specialty drugs are increasingly being used to treat common chronic conditions that affect millions of Americans. ${ }^{8}$ Specialty drug products also represent a growing share of new drug approvals and the late-stage research and development pipeline. ${ }^{9}$ Overall, these trends indicate that a much larger share of the population will use specialty prescription drugs in the future.

Increases in the retail price of specialty prescription drugs have a corresponding impact on the cost of drug therapy for the individual and all other payers. In 2017, the average annual retail cost of prescription drug therapy for a specialty drug, based on the market basket used in this study, was $\$ 78,781$ per year. This average annual cost was almost $\$ 20,000$ more than the median US household income $(\$ 60,336) .{ }^{10}$ It was also more than three times the median income for Medicare beneficiaries $(\$ 26,200),{ }^{11}$ and over four-and-a-half times higher than the average Social Security retirement benefit $(\$ 16,848){ }^{12}$

Notably, the average annual cost of drug therapy for one specialty drug used on a chronic basis would have been almost \$50,000 lower in 2017 (i.e., $\$ 29,843$ v. $\$ 78,781$ ) if the retail price changes had been limited to the rate of general inflation between 2006 and 2017 .

Prescription drug price increases affect all types of payers, including individuals, employers, private insurers, and taxpayer-funded programs such as Medicare and Medicaid. For example, the Medicare Payment Advisory Commission recently noted that high drug prices and drug price increases are a major factor in recent Medicare prescription drug spending growth. ${ }^{13}$ These spending increases, driven by high and growing drug prices, will affect all Americans in some way. Those with private health insurance will pay more in cost sharing and higher premiums for their health care coverage. ${ }^{14}$ In addition, increased government spending on prescription drugs will ultimately lead to higher taxes and/or cuts to public programs.

This report presents annual and 12-year cumulative price changes through the end of 2017. The first set of findings shows annual rates of change in retail prices for widely used specialty drugs from 2006 through 2017, using both rolling average and pointto-point methods (see Appendix A). The point-topoint method examines the distribution of price changes and differences in average percentage changes in retail prices for individual drug products, specific manufacturers, and specific therapeutic categories. The second set of findings summarizes the cumulative impact of retail price changes for specialty drugs that have taken place across the entire 12-year period from 2006 through 2017.

5 CBO, "Specialty Drugs."

6 CBO, "Specialty Drugs."

7 Alan M. Lotvin, William H. Shrank, Surya C. Singh, Benjamin P. Falit, and Troyen A. Brennan, "Specialty Medications: Traditional and Novel Tools Can Address Rising Spending on These Costly Drugs," Health Affairs 33, no. 10 (2014): 1736-44.

8 Ibid.

9 CBO, "Specialty Drugs."

10 Gloria G. Guzman, “Household Income: 2017, American Community Survey Briefs," ACSBR/17-01, US Census Bureau, Washington, DC, September 2018.

11 The median annual income for Medicare beneficiaries was \$26,200 in 2016. Gretchen Jacobson et al., Income and Assets of Medicare Beneficiaries, 2016-2035 (Washington, DC: Kaiser Family Foundation, April 2017).

12 The average monthly Social Security retirement benefit in 2017 was approximately $\$ 1,404$ per month. Social Security Administration, Annual Statistical Supplement to the Social Security Bulletin, 2018, (Washington, DC, Social Security Administration, 2019), https://www.ssa.gov/policy/docs/statcomps/supplement/2018/5b.pdf.

13 Medicare Payment Advisory Commission (MedPAC), June 2018 Report to the Congress: Medicare and the Health Care Delivery System (Washington, DC, MedPAC, June 2018).

14 American Academy of Actuaries, "Issue Brief: Prescription Drug Spending in the U.S. Health Care System: An Actuarial Perspective," American Academy of Actuaries, Washington, DC, March 2018. https://www.actuary.org/sites/default/files/files/publications/ PrescriptionDrugs.030718.pdf. 


\section{Findlings}

\section{SPECIALTY PRICE TRENDS FOR MOST WIDELY USED PRESCRIPTION DRUGS}

In recent years, the annual percentage change in prices for specialty prescription drugs has consistently increased substantially faster than general inflation.

- Retail prices for the 97 specialty drug products ${ }^{15}$ most widely used by older Americans rose 7.0 percent in 2017 compared with 2016 prices (Figure 1). ${ }^{16}$ This average annual increase was lower than the specialty drug price increases observed during the prior decade (i.e., 2008 to 2017), which ranged from 7.1 percent to 9.7 percent.

- The average annual retail price increase in 2017 for these specialty prescription drug products was more than three times higher than the rate of general inflation (7.0 percent v. 2.1 percent). ${ }^{17}$

- In contrast, retail prices for traditional (nonspecialty) brand name drug products

Figure 1

Average Annual Specialty Drug Price Increase Is over Three Times Higher than General Inflation in 2017

Specialty Drug Prices (97 top drug products) $\rightarrow$ General Inflation (CPI-U)

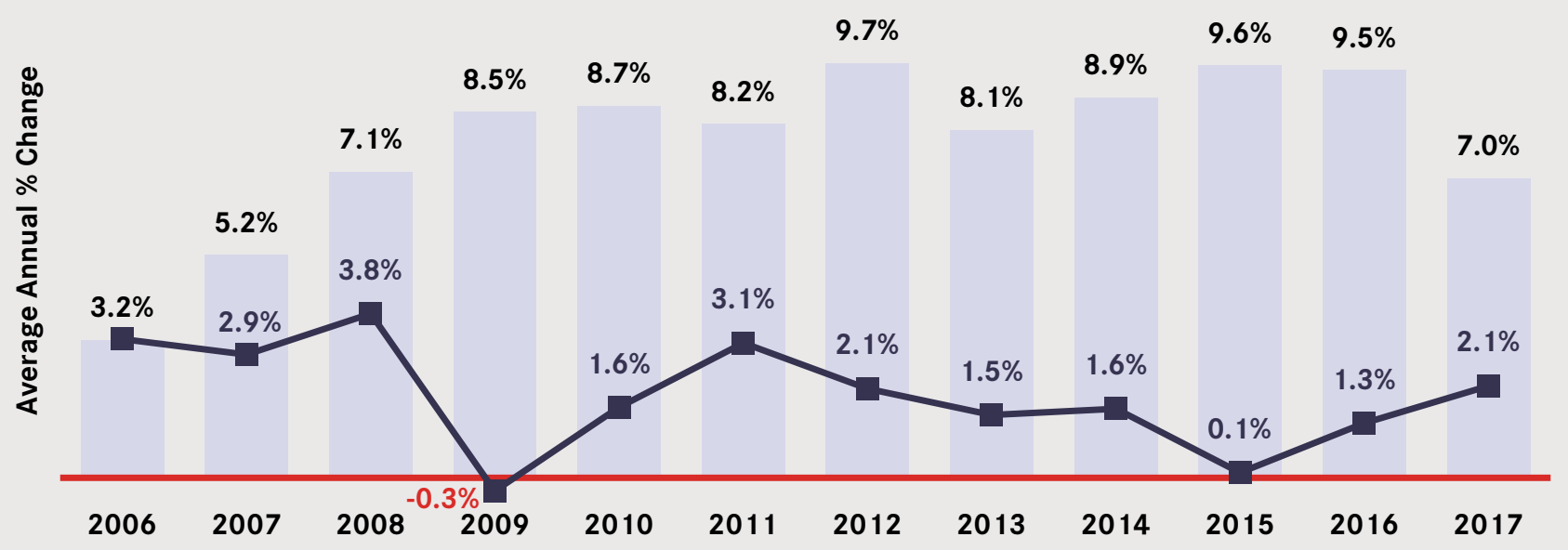

Note: Calculations of the average annual specialty drug price change include the 97 drug products most widely used by older Americans (see Appendix A).

Source: Prepared by the AARP Public Policy Institute and the PRIME Institute, University of Minnesota, based on data from Truven Health MarketScanß Research Databases and MediSpan Price Rx Proß.

15 The market basket for this analysis had 97 specialty prescription drug products. Some critics of the Rx Price Watch reports have suggested that drug products in our market basket that subsequently face generic competition should be excluded from this analysis because they may be skewing the results upward. However, when the 78 specialty drug products with no generic competition were analyzed separately, the average annual price change was 7.4 percent in 2017-higher than the 7.0 percent price trend shown in this report.

16 When measured as a 12-month rolling average and weighted by actual 2014 retail prescription sales to older Americans ages 50 and above, including Medicare beneficiaries.

17 The general inflation rate used in this report is based on the average annual rate of change in the Consumer Price Index-All Urban Consumers for All Items (CPI-U; seasonally adjusted), Bureau of Labor Statistics series CUSR0000SAO. 
most widely used by older Americans rose by 8.4 percent in 2017 , and retail prices for traditional (nonspecialty) generic drug products fell by 9.3 percent in the same year. ${ }^{18}$

The annual retail price change for specialty drug products reported in Figure 1 averages annual point-to-point price changes for each month in the preceding 12-month period (referred to as a rolling average change), smoothing over the entire year the annual change in specialty drug price that occurs for a single month (referred to as an annual point-to-point change).

Figure 2 shows the percentage change in specialty drug prices for each month compared with the same month in the previous year. This trend is presented alongside the 12-month rolling average to allow more detailed examination of the rate and timing of specialty drug price changes over the entire study period. This analysis reveals three broad trends since implementation of the Medicare Part D program in 2006:

- The retail prices of specialty drug products have consistently increased since 2006.

- Specialty drug price increases at the retail level have typically been considerably higher than the corresponding rate of general inflation.

- The gap between the rate of specialty drug price change and the rate of change in general inflation fluctuated but remained sizable for the past 10 years. This gap has ranged from a less than 2 -fold difference to a more than 80 fold difference.

Figure 2

Rolling Average and Point-to-Point Changes in Retail Prices for Most Widely Used Specialty Prescription Drugs Greatly Exceeded Inflation from 2007 to 2017
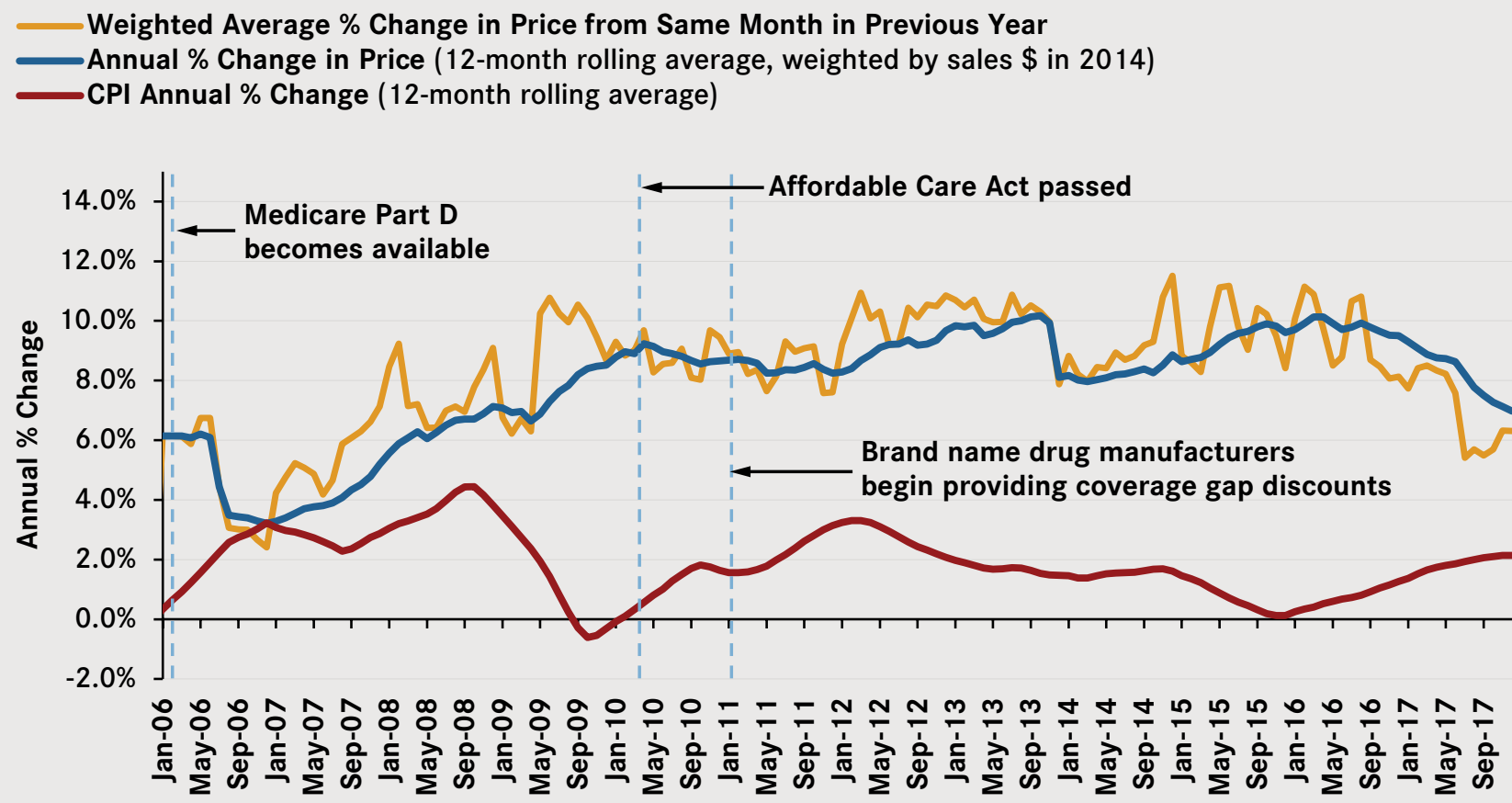

Note: Calculations of the average annual specialty drug price change include the 97 drug products most widely used by older Americans (see Appendix A).

Source: Prepared by the AARP Public Policy Institute and the PRIME Institute, University of Minnesota, based on data from Truven Health MarketScanß Research Databases.

18 Schondelmeyer and Purvis, "Rx Price Watch Report: Brand Name Prescription Drugs"; Schondelmeyer and Purvis, "Rx Price Watch Report: Generic Prescription Drugs.” 


\section{The cost of specialty drug therapy reached $\$ 78,871$ per drug per year in 2017.}

Figure 3 presents the retail price for 61 widely used specialty drugs indicated for treating chronic conditions when the price is expressed as an average annual cost of therapy per drug.

- The average cost of chronic therapy was $\$ 78,871$ per drug per year for specialty prescription drugs at the retail level in 2017.

- This average annual cost $(\$ 78,871)$ is almost triple the average annual cost $(\$ 27,824)$ for a specialty drug in 2006 , the year Medicare implemented Part D.

- The average annual cost of therapy for a single specialty drug in $2017(\$ 78,871)$ was almost $\$ 20,000$ higher than the median US household income $(\$ 60,336)$, more than three times the median income for a Medicare beneficiary $(\$ 26,200)$, and over four-and-a-half times higher than the average Social Security retirement benefit $(\$ 16,848)$ over the same time period. ${ }^{19}$

The average annual retail price of therapy for widely used specialty drugs is considerably higher than the average annual retail cost of therapy for widely used traditional (nonspecialty) brand name and generic drugs. Furthermore, the price differential between these three market baskets is growing rapidly. In 2017, the average annual price of therapy for specialty prescription drugs was almost 12 times higher than the average annual price of therapy for brand name prescription drugs $(\$ 78,781$ v. $\$ 6,798$, respectively) and over 215 times higher than the average annual price of therapy for generic prescription drugs $\left(\$ 78,781\right.$ v. $\$ 365$, respectively). ${ }^{20}$

Figure 4 shows the annual price of therapy for specialty, brand name, and generic drugs in the past six years (2012-17). While the average annual generic price of therapy has decreased by 38.3 percent $(\$ 592$ to $\$ 365)$, the average annual brand name price of therapy has almost

Figure 3

The Average Annual Price of Specialty Drugs Almost Tripled between 2006 and 2017

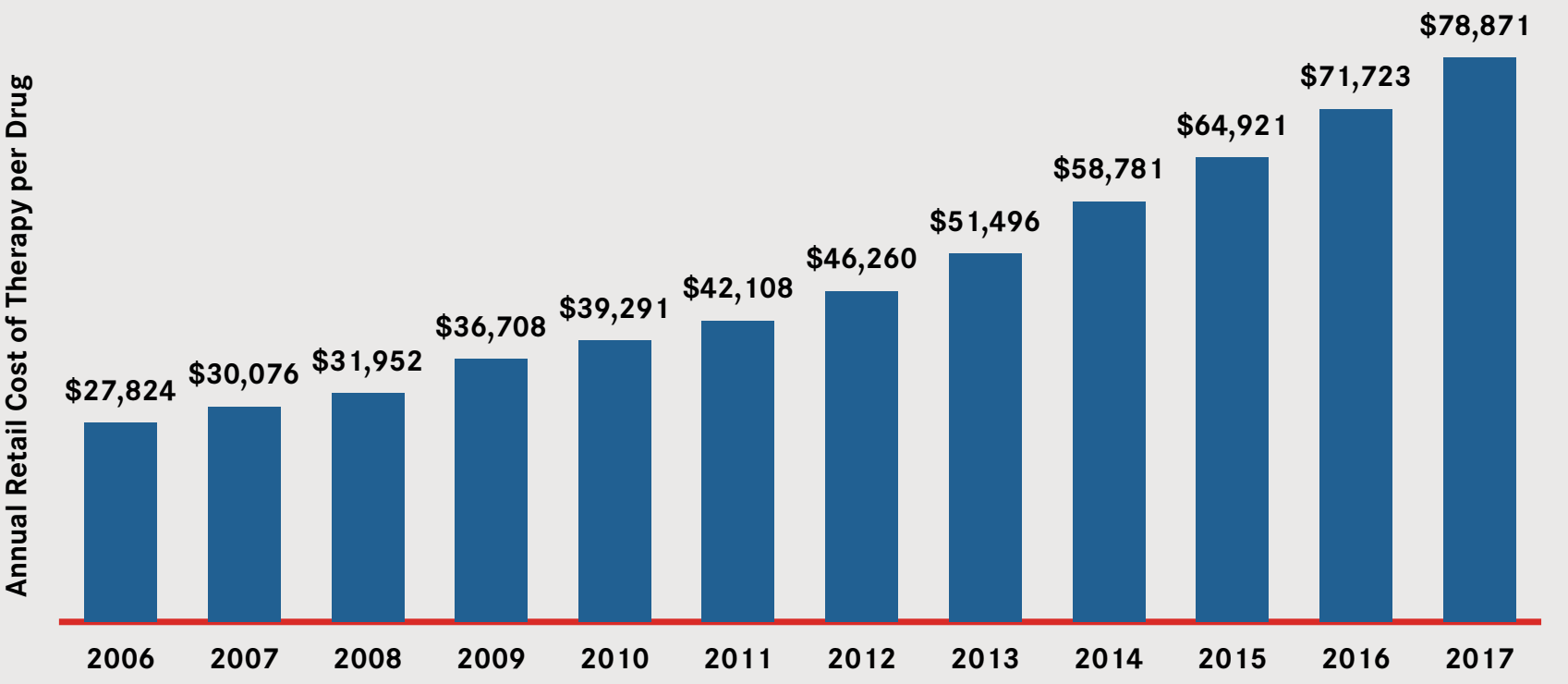

Note: Calculations of the average annual specialty drug price change include the 61 drug products most widely used by older Americans for chronic conditions (see Appendix A).

Source: Prepared by the AARP Public Policy Institute and the PRIME Institute, University of Minnesota, based on data from Truven Health MarketScanß Research Databases.

19 Guzman, "Household Income”; Jacobson et al., Income and Assets; Social Security Administration, Annual Statistical Supplement.

20 Schondelmeyer and Purvis, Rx Price Watch Report: Brand Name Prescription Drugs; Schondelmeyer and Purvis, Rx Price Watch Report: Generic Prescription Drugs. 
Figure 4

The Average Annual Retail Price of Therapy for Specialty Drugs Is Substantially Higher than the Average Annual Retail Price of Therapy for Brand Name and Generic Drugs in 2017
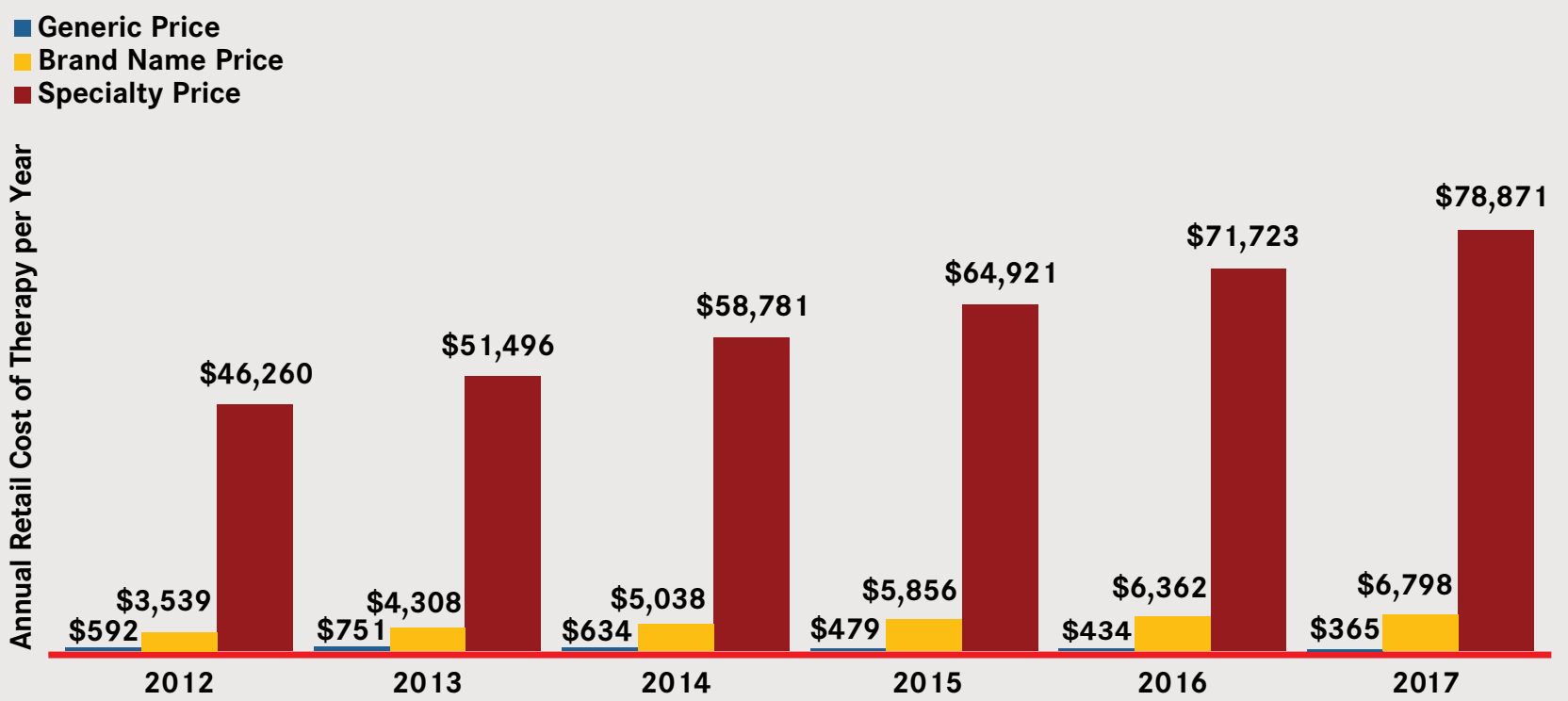

Note: Calculations of average annual drug price of therapy included the drug products most widely used by older Americans for chronic conditions: generic drugs products (260), brand name drug products (214), and specialty drug products (61).

Source: Prepared by the AARP Public Policy Institute and the PRIME Institute, University of Minnesota, based on data from Truven Health MarketScanß Research Databases.

doubled $(\$ 3,539$ to $\$ 6,798)$ and the average annual specialty price of therapy has increased by more than 70 percent $(\$ 46,260$ to $\$ 78,871)$.

While brand name traditional (nonspecialty) drugs had the highest percentage increase $(92$ percent v. 70 percent for specialty drugs) between 2012 and 2017, the specialty drugs had a much more substantial increase in actual monetary value, with a dollar increase from 2012 to 2017 of \$32,611. This very large difference in dollar change stems from the much higher initial price of specialty drugs as they enter the market. For example, a 10 percent price increase for a $\$ 10,000$ drug product is $\$ 1,000$, while the same percent price increase for a $\$ 1,000$ drug product is $\$ 100$.

Notably, the average annual cost of therapy per drug for these same specialty drug products would have been $\$ 29,843$ - almost \$50,000 lower-in 2017 if their retail price changes had been limited to the rate of general inflation between 2006 and 2017 (Figure 5). ${ }^{21}$
II. ANNUAL TRENDS IN PRICE CHANGES FOR MOST WIDELY USED SPECIALTY PRESCRIPTION DRUGS BY FDA APPROVAL PROCESS

The products in the specialty market basket were approved by the US Food and Drug Administration (FDA) using one of the following processes: (a) a new drug application (NDA); (b) a biologic license application (BLA); or (c) an abbreviated new drug application (ANDA). NDAs and ANDAs apply to drug products and medical devices, and BLAs apply to biological products. Of the 97 drug products in the specialty market basket, 70 were NDA approved, 26 were BLA approved, and 1 was ANDA approved.

NDA- and BLA-approved drugs are new brand name drugs, while ANDA-approved drugs are generic drugs. Drug products approved as NDAs, BLAs, and ANDAs differ considerably in their annual percentage change and their annual dollar change in cost of therapy.

21 There is no clear rationale for prescription drug price increases given that launch prices ostensibly reflect the costs associated with developing the drug and future research costs. A. Kesselheim, J. Avorn, and A. Sarpatwari, "The High Cost of Prescription Drugs in the United States: Origins and Prospects for Reform," Journal of the American Medical Association 316, no. 8 (2016): 858-71. 
The Average Annual Cost of Specialty Drugs Would Be Nearly $\$ 50,000$ Lower if Retail Price Changes Were Limited to General Inflation

Cost of Therapy per Drug (Actual)

Cost of Therapy per Drug (Price Growth Limited to General Inflation)

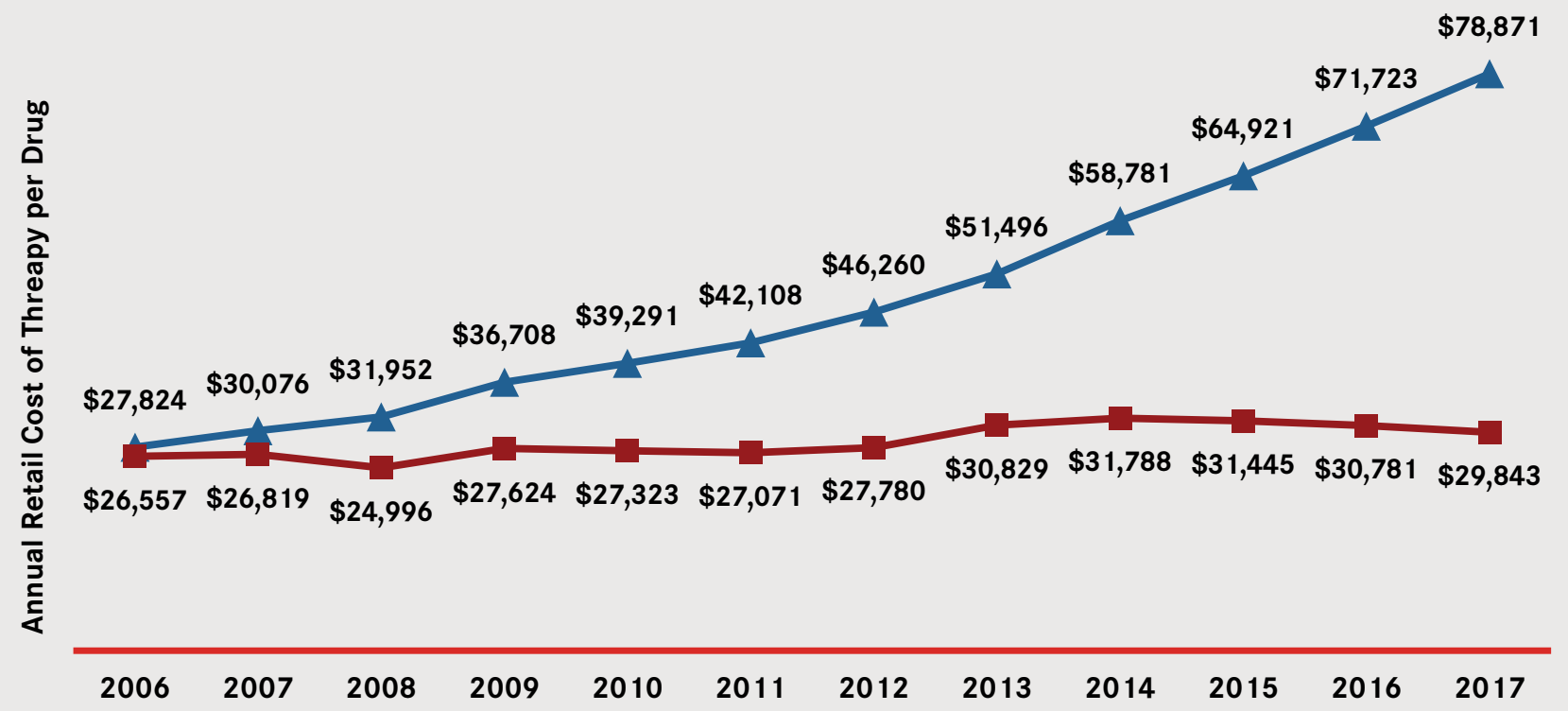

Note: Calculations of the average annual specialty drug price change include the 61 drug products most widely used by older Americans for chronic conditions (see Appendix A).

Source: Prepared by the AARP Public Policy Institute and the PRIME Institute, University of Minnesota, based on data from

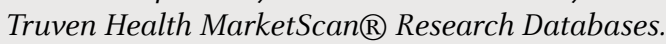

\section{Annual Percentage Change in Retail Prices}

- Retail prices for NDA-approved (brand name) specialty drug products most widely used by older Americans rose by an average of 5.9 percent in 2017. This rate of increase was almost three times higher than the rate of general inflation (2.1 percent) when measured as a 12-month rolling average and weighted by sales to older Americans ages 50 and above. Annual retail price increases for NDA-approved drug products between 2006 and 2014 ranged from 3.4 percent to 10.3 percent (Figure 6).

- Retail prices for BLA-approved (brand name) specialty drug products most widely used by older Americans increased by an average of 10.0 percent in 2017, almost five times higher than the rate of general inflation (2.1 percent). ${ }^{22}$ Annual retail price increases for BLA-approved drug products between 2006 and 2014 ranged from 3.1 percent to 17.1 percent (Figure 6). The price increases of BLA-approved drug products accelerated between 2010 and 2016 (from 6.8 percent in 2010 to 17.1 percent in 2016) and have exceeded the price increases of NDAapproved drugs every year since 2011.

- Retail prices for all brand name specialty drug products (i.e., NDA- and BLA-approved drug products) most widely used by older Americans increased at an average rate of 9.6 percent in 2016 and 7.1 percent in 2017. In contrast, retail prices for brand name nonspecialty drug products most widely used by older Americans increased by an average

22 The Affordable Care Act of 2010 contained a provision that granted FDA the authority to approve less-expensive generic (biosimilar or interchangeable) versions of BLA-approved specialty drugs. However, FDA has yet to finalize all of the regulations needed to fully implement this new authority and relatively few biosimilars have entered the market. Thus, biologic drug manufacturers still do not face meaningful generic competition after biologic patents expire. 


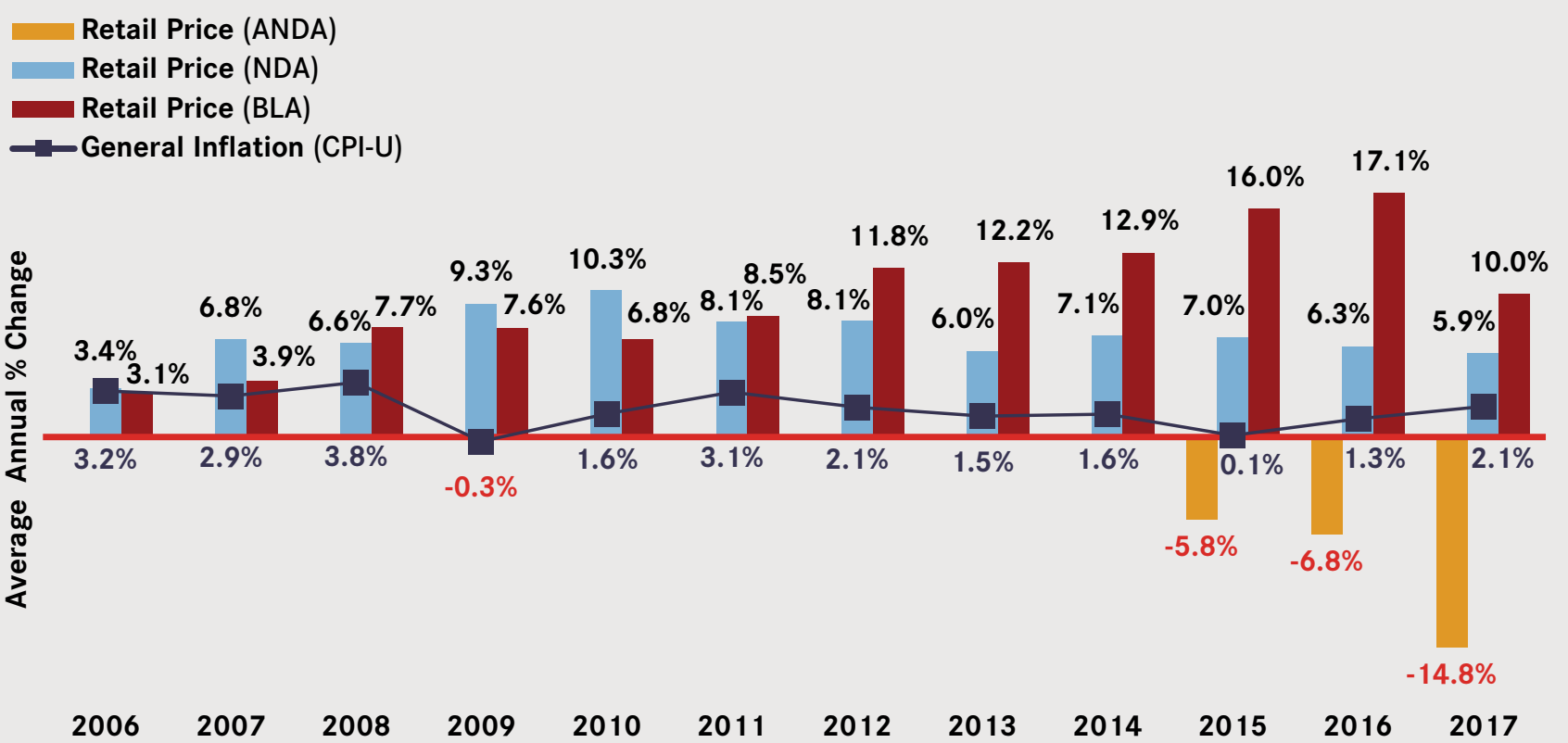

Note: Calculations of average annual specialty drug price change include 97 drug products most widely used by older Americans: ANDAs (1), NDAs (70), and BLAs (26).

Source: Prepared by the AARP Public Policy Institute and the PRIME Institute, University of Minnesota, based on data from Truven Health MarketScan Research Databases.

of 13.7 percent and 8.4 percent, respectively, in those years. ${ }^{23}$

- In contrast, the retail prices of the single ANDA-approved (generic) specialty drug product most widely used by older Americans decreased by 14.8 percent in 2017. Similarly, the retail prices for generic nonspecialty drug products most widely used by older Americans decreased at an average rate of 9.3 percent over the same time period. ${ }^{24}$

\section{Annual Retail Cost of Therapy}

We translated retail price changes into average annual cost of therapy (Figure 7) for the widely used specialty drugs for treating chronic conditions. Of the 61 drugs in the market basket used to treat chronic conditions, 40 were NDAs, 21 were BLAs, and none were ANDAs.

- A person who took an NDA-approved specialty prescription drug had an average annual cost of therapy of $\$ 91,385$ in 2017 , assuming that the consumer used the specialty drug for a chronic condition. The average annual cost of therapy for NDA-approved specialty drugs increased by 109 percent since 2006, the year Medicare implemented Part D.

- $\quad$ The average annual cost of therapy for $B L A$ approved specialty prescription drugs was $\$ 64,747$ in 2017. The average annual cost of therapy for BLA-approved specialty drugs increased by 241 percent since 2006, the year Medicare implemented Part D.

\section{TWELVE-YEAR CUMULATIVE RETAIL} PRICE CHANGES FOR MOST WIDELY USED SPECIALTY PRESCRIPTION DRUGS, 2006-17 This AARP report tracked specialty drug prices at the retail level for the 12-year period from December 31, 2005, to December 31, 2017. Twentyeight percent (27 of 97) of the widely used drugs in the specialty market basket were on the market for the entire 12-year period (i.e., the end of 2005 through the end of 2017).

23 Schondelmeyer and Purvis, Rx Price Watch Report: Brand Name Prescription Drugs.

24 Schondelmeyer and Purvis, Rx Price Watch Report: Generic Prescription Drugs. 
Figure 7

The Average Annual Cost of Therapy Increased by More than 240 Percent for Widely Used BLAApproved Specialty Prescription Drugs between 2006 and 2017

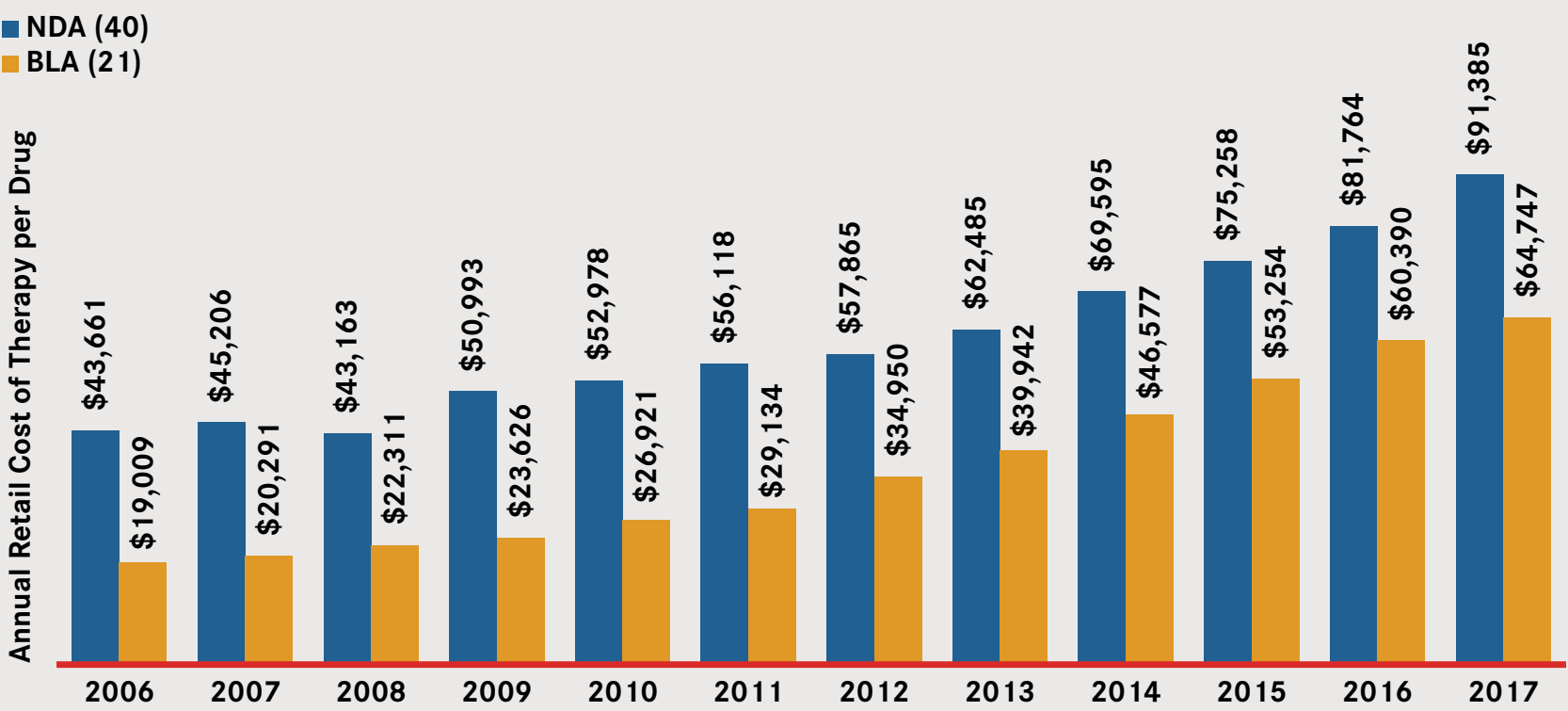

Note: Calculations of average annual drug price of therapy included the 61 drug products most widely used by older Americans for chronic conditions: NDAs (40) and BLAs (21).

Source: Prepared by the AARP Public Policy Institute and the PRIME Institute, University of Minnesota, based on data from Truven Health MarketScan® Research Databases.

Cumulatively, the average retail price for these 27 widely used specialty drug products increased 226.4 percent over 12 years, compared with a 25.1 percent increase in general inflation during the same period. This means that specialty drug prices increased more than nine times faster than the rate of general inflation during this time period.

\section{The 12-year cumulative change in annual specialty drug cost of therapy is substantial.}

Of the specialty drug products in the AARP market basket that have been on the market since the end of 2005, 74 percent (20 of 27) treat chronic conditions. ${ }^{25}$ The remaining 7 drug products treat acute or intermittent conditions.

The average annual retail cost of drug therapy for specialty drug products on the market since the end of 2005 and used to treat chronic conditions was $\$ 62,406$ in 2017 , which is an increase of $\$ 42,737$ over the 2006 annual cost of $\$ 19,669$.
Three-quarters ( 15 of 20 ) of the specialty drugs used for chronic conditions that have been on the market since the end of 2005 had annual cost of therapy increases of more than $\$ 10,000$ during the 12-year period ending in 2017.

\section{MORE THAN 8 OUT OF 10 WIDELY USED SPECIALTY DRUGS INCREASED IN PRICE} FASTER THAN GENERAL INFLATION IN 2017 Of the most widely used specialty drug products, 82 percent (80 of 97) had retail price increases that met or exceeded the rate of general inflation (2.1 percent) in 2017 (Figure 8).

Sixty percent (58 of 97) of the most widely used specialty drug products had retail price increases of between 5.0 percent and 9.9 percent.

Among the 18 percent (17 of 97) of specialty drug products with annual price increases of 10.0 percent or more in 2017,

- Nine (9 percent) increased by 10.0 percent to 14.9 percent;

25 We classified the drug products in our study market basket based on whether the primary indication for use was for a chronic condition or an acute (or intermittent) condition. 
- Five (5 percent) increased by 15.0 percent to 19.9 percent; and

- Three (3 percent) increased by 20.0 percent or more.

The single highest retail price increase for a specialty drug product in the market basket was for Revatio (20 mg tablet, used to treat pulmonary hypertension). Revatio's retail price rose by 48.1 percent between 2016 and 2017 (Figure 9). The second highest retail price increase among the most widely used specialty drugs was Revlimid (10 mg capsule, used to treat cancer), which had an annual price increase of 21.4 percent in 2017 compared with 2016. Prolastin-C (1,000 mg, used to treat emphysema) also had a price increase between 2016 and 2017 of more than 20 percent.

One of the 97 top specialty drug products was a generic drug product. This generic drug (capecitabine $500 \mathrm{mg}$ tablet, used to treat cancer) had a price decrease, along with 9 other drug products (Figure 10). Seven other drug products did not experience a price change between 2016 and 2017.

All but 5 of the 30 top-selling specialty drug products in the market basket had retail price increases in 2017 when compared with 2016 (Table 1). Each of these 25 top-selling specialty drug products had a price increase that was higher than the rate of general inflation (2.1 percent) in 2017.

Of the top 30 specialty drug products, 5 had retail price increases of 12.6 percent or more in 2017-at least six times the rate of general inflation. The highest retail price increase in 2017 among the top 30 specialty drug products was 21.4 percent for Celgene's Revlimid $10 \mathrm{mg}$ capsule, used to treat cancer (Figure 9).

Five widely used specialty drug products experienced retail price decreases of -0.2 percent to -4.4 percent between 2016 and 2017.

\section{RETAIL PRICE CHANGES FOR MOST WIDELY USED SPECIALTY PRESCRIPTION DRUGS BY MANUFACTURER}

Thirty drug manufacturers had at least 1 drug product in the study's market
Figure 8

Retail Prices Increased for More than 80 Percent of Most Widely Used Specialty Drugs in 2017

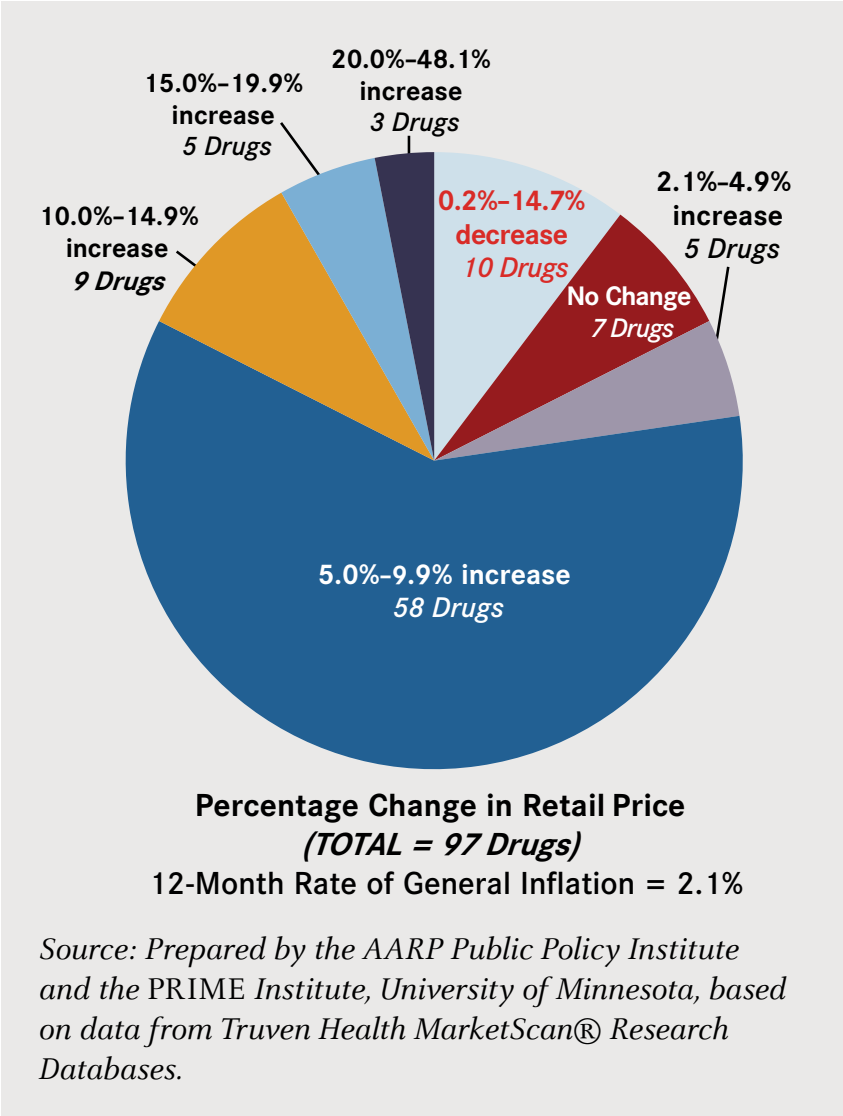

Retail Prices for Three Widely Used Specialty Drugs Increased by More than 20 Percent in 2017

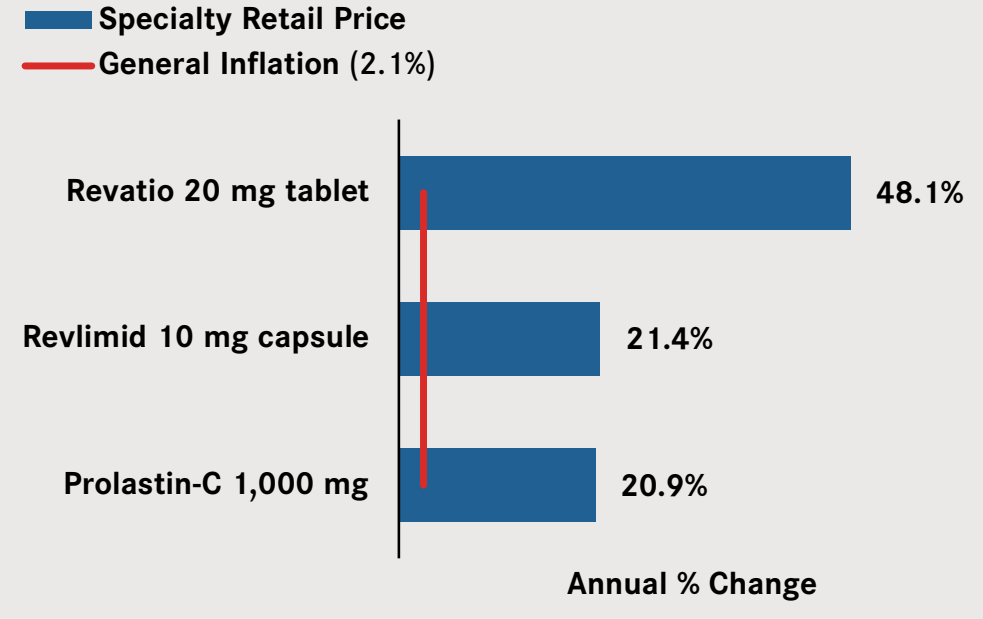

Source: Prepared by the AARP Public Policy Institute and the PRIME Institute, University of Minnesota, based on data from Truven Health MarketScan® Research Databases. 


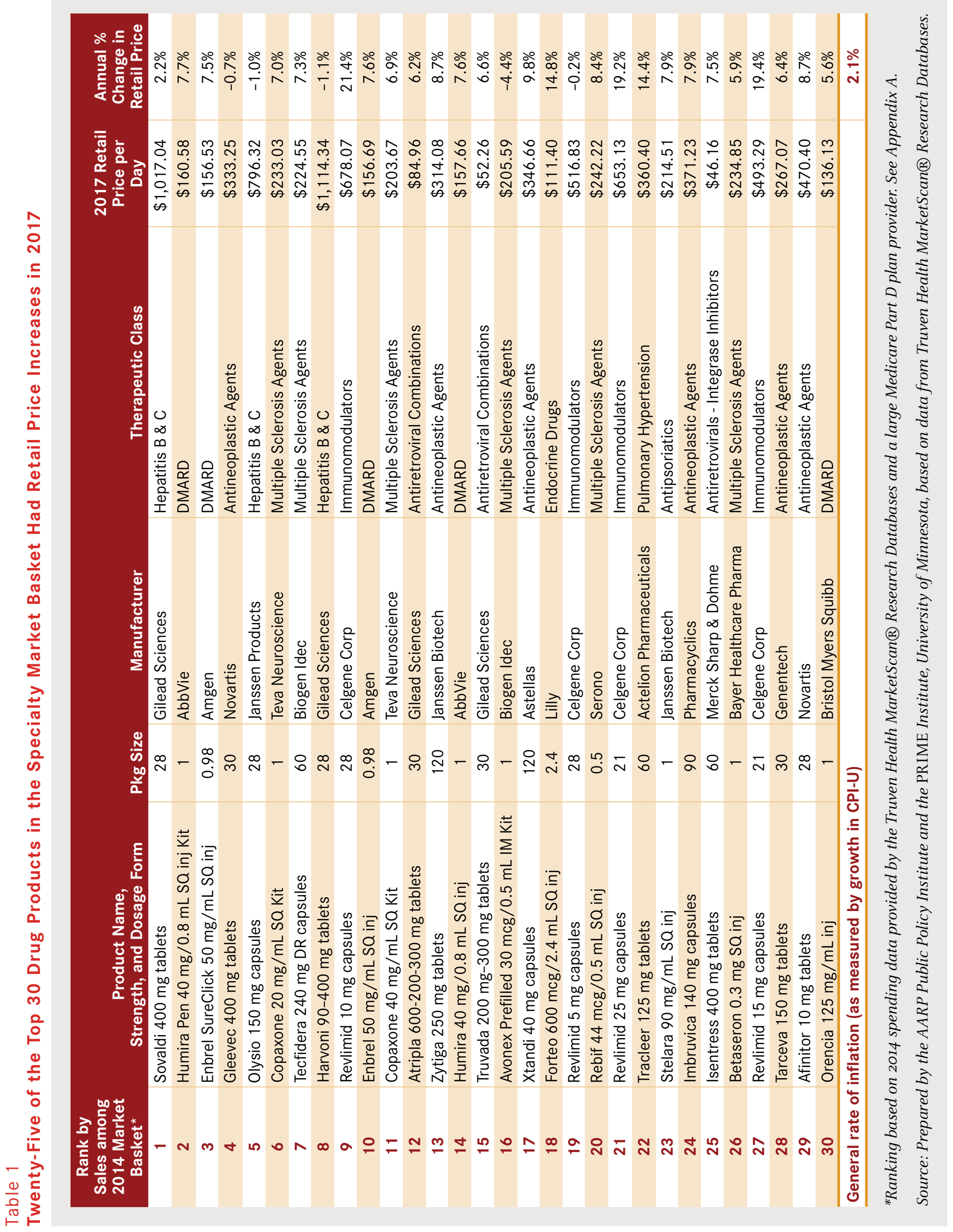


basket of 97 widely used specialty drugs. The average annual increase in retail price for 83 percent ( 25 out of 30 ) of these drug manufacturer categories exceeded the general inflation rate in 2017 (Figure 11), suggesting that there is a broad-based specialty drug price increase trend.

- $\quad$ Twenty-two drug manufacturers (73 percent) had weighted average annual specialty drug price increases of 4.2 percent or more in 2015 - or at least twice the rate of general inflation (2.1 percent) in 2017.

- Three drug manufacturers had weighted average specialty drug price increases of more than 15.0 percent in 2017 , or more than seven times the rate of general inflation (2.1 percent) in 2017.

- Celgene and Pfizer had weighted average annual price increases of 16.3 percent and 16.8 percent, respectively, in 2017-or roughly eight times the rate of general inflation.

- Grifols USA had a weighted average annual price increase of 20.9 percent in 2017-or nearly 10 times the rate of general inflation.

- Two drug manufacturers with only one product in the study's market basket-Valeant and United Therapeutics Corp-had no change in their weighted average annual price in 2017.

- One manufacturer (Baxalta, four drug products) had a weighted average annual retail price decrease of 1.6 percent in 2017.

\section{RETAIL PRICE CHANGES FOR MOST WIDELY USED SPECIALTY PRESCRIPTION DRUGS BY THERAPEUTIC CATEGORY}

Specialty drug prices at the retail level increased faster than the rate of general inflation (2.1 percent) in 2017 for 90 percent (19 of 21) of the therapeutic categories examined in this study (Figure 12). All 19 of the therapeutic categories
Figure 10

Retail Prices for 10 Widely Used Specialty Prescription Drugs Decreased in 2017

\section{Specialty Retail Price}

General Inflation (2.1\%)

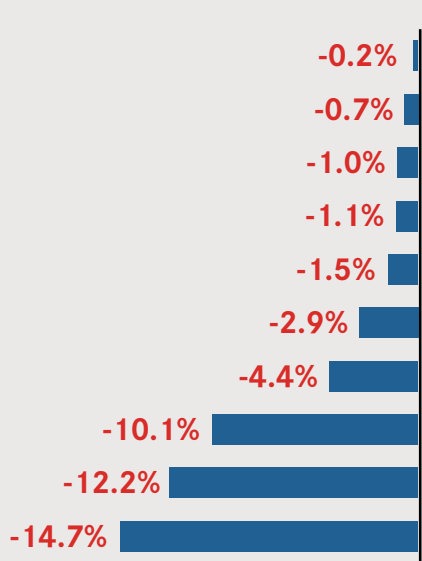

Annual \% Change
Source: Prepared by the AARP Public Policy Institute and the PRIME Institute, University of Minnesota, based on data from Truven Health MarketScan Research Databases.

\author{
Revlimid 5 mg capsule \\ Gleevec $400 \mathrm{mg}$ tablet \\ Olysio $150 \mathrm{mg}$ capsule \\ Harvoni 90-400 mg tablet \\ Votrient $20 \mathrm{mg}$ tablet \\ Epzicom 600-300 mg tablet \\ Avonex $30 \mathrm{mcg} / 0.5 \mathrm{~mL}$ kit \\ Gleevec $100 \mathrm{mg}$ tablet \\ Gammagard inj $30 \mathrm{gm} / 300 \mathrm{~mL}$ \\ Capecitabine $500 \mathrm{mg}$ tablets
}

with an increase in price averaged annual price increases of 5.0 percent or greater-more than twice the rate of general inflation in 2017.

- Fifteen therapeutic categories had average annual price increases of 6.3 or higher - or three times the rate of general inflation in 2017 (2.1 percent).

- Five therapeutic categories had average annual price increases of 10.5 percent or higher-or five times the rate of general inflation in 2017.

- The therapeutic category with the highest specialty drug price increase was immunomodulators - used to regulate the immune system-with an average annual retail price increase of 16.1 percent in 2017.

- One of the 21 therapeutic categories (Hepatitis B \& C) experienced a relatively small retail price increase of 1.1 percent in 2017, and 1 therapeutic category (Immune Serums) had a weighted average annual retail price decrease of -1.6 percent. 
Figure 11

Twenty-Five of 30 Drug Manufacturers Had Retail Price Increases That Exceeded the Rate of General Inflation in 2017

Specialty Retail Price

General Inflation (2.1\%)

Grifols USA (1)

Pfizer (5)

Celgene Corp (6)

Actelion Pharm (2)

Lilly (2)

Incyte Corporation (3)

Jazz Pharmaceuticals (1)

Acorda Therapeutics (1)

UCB Pharma (1)

Serono (3)

Shire (2)

Pharmacyclics (1)

Merck Sharp \& Dohme (1)

AbbVie (4)

Amgen (6)

Genentech (4)

Bayer Healthcare Pharma (3)

B-M Squibb (5)

Astellas (1)

Janssen/Janssen Biotech (13)

Teva Neuroscience (3)

Viropharma, Inc (1)

Genzyme (1)

Biogen Idec (3)

Gilead Sciences (9)

Novartis (7)

Viiv Healthcare (2)

United Therapeutics Corp (1)

Valeant (1)

Baxalta (4) $-1.6 \%$
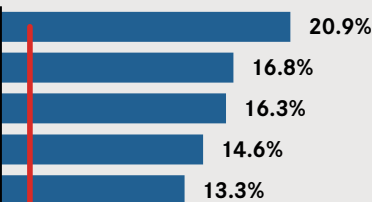

$13.3 \%$
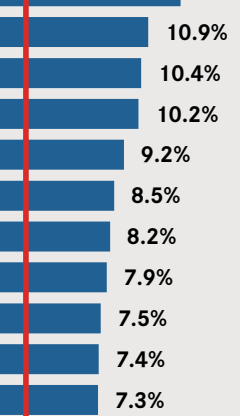

$7.2 \%$
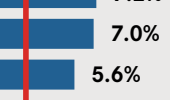

$5.5 \%$

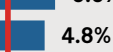

$4.8 \%$
$-1.4 \%$

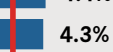

$4.3 \%$

$3.7 \%$

$3.4 \%$

$3.1 \%$

$1.3 \%$

$0.3 \%$

$0.0 \%$

$0.0 \%$

Average Annual \% Change

Note: Calculations include the 97 specialty prescription drug products most widely used by older Americans (see Appendix A). The number in parentheses after a manufacturer's name indicates the number of drug products in the market basket for that manufacturer. The general inflation rate is based on CPI-U All Items for 2017.

Source: Prepared by the AARP Public Policy Institute and the PRIME Institute, University of Minnesota, based on data from Truven Health MarketScan@ Research Databases.
Figure 12

All but Two Therapeutic Categories for

Specialty Drugs Had Retail Price Increases That

Exceeded the Rate of General Inflation in 2017

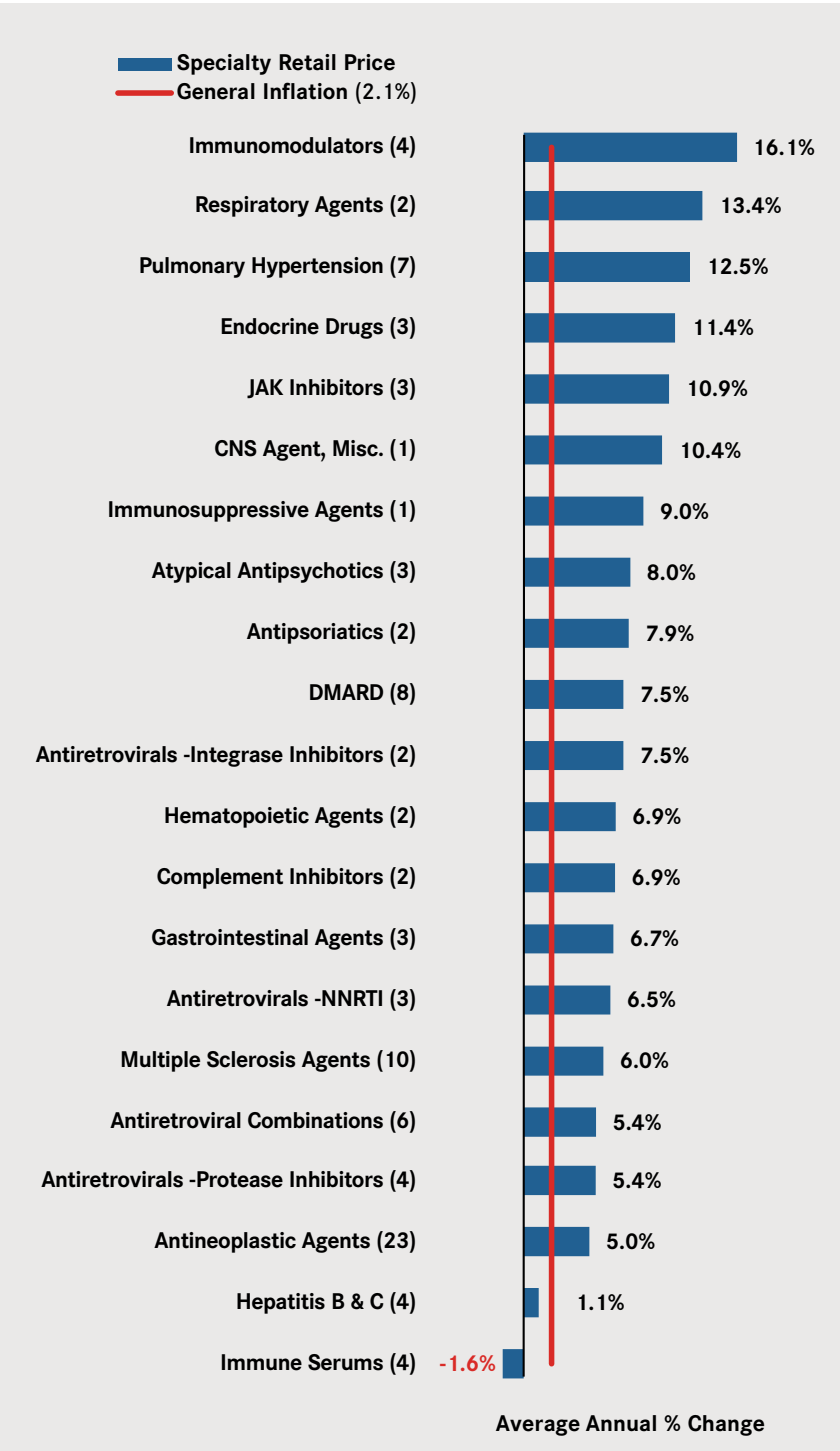

Note: Calculations include the 97 specialty prescription drug products most widely used by older Americans (see Appendix A). See Appendix B for an explanation of therapeutic category acronyms. The number in parentheses after a therapeutic category indicates the number of drug products in the market basket for that therapeutic category. The general inflation rate is based on the CPI-U All Items for 2017. 
Specialty drug prices have routinely increased much faster than general inflation over the more than 12 years that this report series has been tracking prescription drug prices. In 2017, the average annual increase in retail prices for 97 specialty prescription drugs widely used by older Americans, including Medicare beneficiaries, was 7.0 percent. In contrast, general inflation in the United States rose by 2.1 percent in 2017.

Increases in the retail price of specialty prescription drugs affect both patients and the broader economy. In 2017, the average annual retail cost of prescription drug therapy for a specialty drug, based on the market basket used in this study, was $\$ 78,781$ per year. This average annual cost was almost $\$ 20,000$ more than the median US household income $(\$ 60,336) .{ }^{26}$ It was also more than three times the median income for Medicare beneficiaries $(\$ 26,200),{ }^{27}$ and over fourand-a-half times higher than the average Social Security retirement benefit $(\$ 16,848)^{28}$ in 2017. Notably, the average annual cost of drug therapy for one specialty drug used on a chronic basis would have been almost \$50,00o lower in 2017 (i.e., $\$ 29,843$ v. $\$ 78,781$ ) if the retail price changes had been limited to the rate of general inflation between 2006 and 2017.
While specialty drug products are used by a relatively small, but growing, share of the overall population, they account for the fastestgrowing portion of US drug expenditures in recent years. ${ }^{29,30}$ There are strong indications that specialty drugs will become the largest share, and the majority, of drug expenditures in the next few years. If recent trends in specialty drug prices and related price increases continue, it will almost undoubtedly become more difficult for patients to access and afford necessary specialty medications. Spending increases driven by high and growing specialty drug prices affect all Americans in some way. Those with private health insurance will pay higher premiums and/or cost sharing for their health care coverage ${ }^{31}$ and government programs will grow faster than the tax-based revenue that supports them, leading to higher taxes and/or to cuts to public health or other health benefit programs.

Policy makers interested in reducing the impact of prescription drug prices should focus on options that drive significant innovation while also protecting the health and financial security of consumers and taxpayer-funded programs like Medicare and Medicaid.

26 Guzman, "Household Income."

27 The median annual income for Medicare beneficiaries was $\$ 26,200$ in 2016. Jacobson et al., Income and Assets.

28 The average monthly Social Security retirement benefit in 2017 was approximately $\$ 1,404$ per month. Social Security Administration, Annual Statistical Supplement.

29 Department of Health \& Human Services, Office of the Assistant Secretary for Planning and Evaluation (ASPE), "Observations on Trends in Prescription Drug Spending," ASPE Issue Brief, ASPE, Washington, DC, March 8, 2016.

30 CBO, Specialty Drugs.

31 American Academy of Actuaries, "Issue Brief." 


\section{Appendix A \\ Detailed Methodology and Description of Retail Price Data}

This appendix describes in detail how brand name, generic, and specialty drugs are defined in this study; how the study identified the market basket (i.e., sample) of drugs; how it measured prices; and how it calculated weighted average price changes. In addition, the appendix describes methods and assumptions used to determine prices and price changes by drug manufacturer and by therapeutic category.

\section{OVERVIEW}

AARP's Public Policy Institute has been publishing a series of reports that track price changes for the prescription drug products most widely used by older Americans, with annual and quarterly results reaching as far back as 2000 . Since 2008, these reports have focused on price changes for three market baskets-brand, generic, and specialty drugs. In addition, a combined market basket (i.e., brand, generic, and specialty) has been added to the series, which is useful to view the price change trend across all types of outpatient prescription drugs in the US market. While this overall perspective is useful for those interested in understanding the industrial economics of the entire prescription drug market, consumers have proven to be considerably more interested in the price trend for the specific products that they are taking as individuals rather than all drug products on the market.

The AARP Public Policy Institute and the University of Minnesota's PRIME Institute originally collaborated to report an index of manufacturers' drug price changes based on the Wholesale Acquisition Cost (WAC) from the Medi-Span Price-Chek PC database. ${ }^{1}$ In 2009, AARP and the PRIME Institute created an additional drug price index based on actual

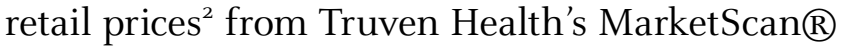
Commercial Database and MarketScan $\AA$ Medicare Supplemental Database (Truven Health MarketScan® Research Databases). ${ }^{3}$ Thus, the report series uses the same market basket of brand name prescription drugs widely used by older Americans to examine both manufacturerlevel prices and retail-level prices in the market. The addition of retail-level prices allows the AARP Public Policy Institute to assess what prices payers (i.e., insurers, consumers, or government programs) are paying and whether rebates and other types of discounts have been passed along to payers and their covered members.

Recently, the AARP Public Policy Institute and the University of Minnesota's PRIME Institute collaborated to develop a new market basket of widely used prescription drugs based on 2014 data

1 Medi-Span is a private organization that collects price and other clinical and drug-related data directly from drug manufacturers and wholesalers. Price-Chek PC (now Price Rx Pro $R$ ) is a product of Medi-Span (Indianapolis, IN), a division of Wolters Kluwer Health Inc., and uses data from Medi-Span's Master Drug Database (MDDB $®)$. This commercial drug database has been published for more than 35 years. See http://www.medispan.com.

2 The retail prices used in this report series reflect the total price for a specific prescription that a PBM bills to a specific health plan for consumers enrolled in employer-sponsored or government-sponsored (i.e., Medicare or Medicaid) health plans and not simply the out-of-pocket cost (such as the copay) that a consumer would pay at the pharmacy. These amounts may or may not reflect what the PBM paid the pharmacy or the usual and customary price that a pharmacy would charge a cash-pay consumer for the same prescription.

3 The Truven Health MarketScan ${ }^{\circledR}$ Research Databases, a family of databases, contain individual-level health care claims, lab test results, and hospital discharge information from large employers, managed care organizations, hospitals, Medicare, and Medicaid programs. Truven Health constructs the MarketScan ${ }^{\circledR}$ Research Databases by collecting data from employers, health plans, and state Medicaid agencies and placing them into databases. Erica Danielson, "White Paper: Health Research Data for the Real World: The MarketScan ${ }^{\circledR}$ Databases,” White Paper, Truven Health Analytics, Ann Arbor, MI, January 2014. 
provided by the Truven Health MarketScan Research Databases and a large Medicare Part D plan provider. UnitedHealthcare provides Medicare Part D coverage and is the organization that insures the AARP Medicare Rx plans. This Medicare Part D plan provider supplied data for all prescriptions provided to its Medicare Part D enrollees in 2014. This Rx Price Watch report used the 2014 market basket. ${ }^{4}$ As in the past, the series will include separate data sets, analyses, and reports for brand name, generic, and specialty drugs, as well as the overall combined market basket.

\section{DEFINING BRAND, GENERIC, AND SPECIALTY PHARMACEUTICALS}

A brand name drug is defined as a product marketed by the original holder of a new drug application (NDA, or related licensees) or a biological license application (BLA; or related licensees) for a given drug entity. A generic drug is defined as any drug product marketed by an entity other than the NDA or BLA holder or the related licensees.

The market conditions and pricing behavior for brand name and generic drugs are quite different. For example, brand name drugs have a monopoly based on patents and other forms of exclusivity for a number of years after market entry, ${ }^{5}$ and they do not experience typical price competition from therapeutically equivalent (i.e., AB-rated generic equivalents) drug products that can be routinely and directly substituted at the pharmacy level. On the other hand, generic drug products typically face price competition from the time the generic first enters the market, when there are two or more therapeutically equivalent drug products (as evaluated by the Food and Drug Administration [FDA] and reported in the Orange Book), including the brand name product. However, certain generic drugs - that is, those for which the generic manufacturer files a paragraph IV certification of patent non-infringement-may receive 180 days of exclusivity as the sole generic after this first generic drug product is approved. In cases in which there is only one generic drug product on the market, the level of economic competition may be somewhat limited until other economically independent generic marketers enter the market.

Specialty pharmaceuticals are drugs that treat complex, chronic conditions and that often require special administration, handling, and care management. Specialty drugs have been the fastest-growing group of new drug products over the next decade. This important group of drugs and biologicals is not precisely defined, but it includes products based on one or more of the following: (1) how they are made, (2) how they are approved by the FDA, (3) conditions they treat, (4) how they are used or administered, (5) their cost, and (6) other special features. The operational definition of specialty drugs for this study is further described in a later section on the methodology.

\section{CREATING THE MARKET BASKET OF DRUGS}

The AARP Public Policy Institute has been reporting prescription drug product price changes since 2004. The original reports were based on a market basket of retail and mail-order prescriptions provided to about 2 million people ages 50 and older who used the AARP Pharmacy Service in 2003. Following the implementation of the Medicare Part D program, we chose to develop a new market basket of drugs using 2006 data provided by UnitedHealthcare (formerly called PacifiCare), which is also the organization that insures the AARP Medicare Part D plans. All AARP price trend reports published between 2007 and 2012 used this market basket.

Subsequently, we updated the AARP market baskets again using 2011 data provided by Truven Health MarketScan® Research Databases and the same Medicare Part D plan provider that was used for the 2006 market basket. We weighted the data from the Medicare Part D plan provider by Part D enrollment and the Truven Health MarketScan $\AA$ data by the 50-plus population less Part D enrollment, based on data from the

4 The US Food \& Drug Administration approved 113 new drugs and biological products between 2015 and 2017. These products are not included in our current market basket but will be included in future market baskets if they meet our inclusion criteria. US Food \& Drug Administration, New Drugs at FDA: CDER's New Molecular Entities and New Therapeutic Biological Products, accessed September 1, 2018. https://www.fda.gov/Drugs/DevelopmentApprovalProcess/DrugInnovation/default.htm.

5 The average market exclusivity period for a brand name drug is almost 13 years. Henry Grabowski, Genia Long, and Richard Mortimer, "Brief Report: Recent Trends in Brand-Name and Generic Drug Competition," Journal of Medical Economics 17, no. 3 (2014): $207-14$. 
Centers for Medicare and Medicaid Services and the US Census. We then merged the weighted data to develop and rank a weighted master list by prescription volume and sales at the National Drug Code (NDC) level for the new AARP market baskets.

This process was repeated using 2014 data provided by the same data sources. The 2014 market basket is the basis of this report and the 2015 through 2017 Rx Price Watch reports.

Our selection of the market basket of drugs to track in the price index was a multistep process. First, prescriptions covered and adjudicated by the commercial entities included in the merged data set were grouped by NDC number. The NDC is a number that refers to a specific drug product presentation with a unique combination of active chemical ingredient, strength, dosage form, package type and size, and manufacturer (e.g., Nexium [esomeprazole magnesium] $40 \mathrm{mg}$, capsule, bottle of 30, AstraZeneca). As a result, some drug entities (i.e., molecules) could appear more than once among the widely used drug products (e.g., when there are different strengths, such as Lipitor $10 \mathrm{mg}$, Lipitor $20 \mathrm{mg}$, and Lipitor $40 \mathrm{mg}$ ). For each NDC, we calculated total sales revenue from adjudicated prescription claims, including the patient cost-sharing amount, as well as the total prescriptions dispensed, the total units supplied, and the total days of therapy provided during 2014 .

The next step involved merging the use and expenditure data from the Truven Health MarketScan@ Research Databases and the Medicare Part D plan provider by NDC code and then linking the data with descriptive information from Medi-Span's Price Rx Pro® drug database, ${ }^{6}$ using the NDC number as the key linking variable. The descriptive data from Price Rx Pro included drug product information such as brand name, generic name, manufacturer, patent status, package size, route of administration, usual dose, therapeutic category, usual duration, and each price history.

All NDCs were classified by the patent status of the drug product presentation-that is, patented brand name (i.e., brand single source [SS]), off- patent brand name (i.e., brand multiple source [BMS] or innovator multiple source [IMS]), and offpatent generic (i.e., generic multiple source [GMS] or non-innovator multiple source [NMS]). We then grouped all NDC numbers by the Generic Product Indicator (GPI) code into GPI-patent status groups using the GPI code from Price Rx Pro®. The GPI combines drug products into a common group when they have the same active ingredients, dosage form, and strength - a single GPI includes the NDCs for any package type and size and from all manufacturers. When patent status is combined with the GPI categories, each GPI will typically be either a single source GPI (GPI-brand single source) or a multiple source GPI with both a GPI-brand multiple source group and a GPIgeneric multiple source group.

The next step involved summing the total expenditures, number of prescriptions dispensed, and days of therapy provided across all NDCs within each GPI-patent status group. The NDCs within each GPI-patent status group were then rank ordered based on total annual expenditure for each NDC. The designated "representative NDC" was the NDC that had the highest level of expenditure within each GPI-patent status group. If the NDC with the greatest expenditure level was inactive, then the NDC with the next highest level of expenditure became the representative NDC.

This analysis excluded less than 0.5 percent of the expenditures and the prescriptions because they were for nondrug items. These nondrug items included devices, medical and diabetic supplies, syringes, compounding service fees, and other professional services. After exclusion of nondrug items, the 2014 data set contained 36,866 NDCs grouped into 6,085 GPI-patent status categories.

We then coded all GPIs to distinguish the specialty prescription drugs from other regular, or traditional, prescription drugs. The definition of specialty prescription drugs used here is a prescription drug that is (1) administered by injection, such as intravenous, intramuscular, sub-cutaneous, or other injection site (not including insulin); (2) a drug product approved by the FDA through a BLA (biological license

6 Price Rx Pro ${ }^{R}$ is a product of Medi-Span (Indianapolis, IN), a division of Wolters Kluwer Health, Inc., and is based on data from MediSpan's MDDBR. 
application); (3) any drug product that has a total average prescription cost greater than $\$ 1,000$ per prescription; or (4) any drug product that has a total average cost greater than $\$ 33$ per day of therapy. The drug products meeting this definition were considered "specialty drugs" and all other prescription drugs were considered "regular," "traditional," or "nonspecialty" drugs. Throughout this report, references to the market basket of drugs refer to the regular (nonspecialty) drugs unless otherwise indicated. Only specialty drugs provided through a Medicare Part D program or under a prescription drug benefit program are included. The specialty drugs provided under Medicare Part B, or under a commercial health plan and administered in a clinic or physician's office and billed as a medical claim, are not included in this data set or this analysis.

All NDCs were classified by the patent status of the drug product presentation-that is, patented brand name (or SS), off-patent brand name (or IMS), or off-patent generic (NMS). We classified both the regular and the specialty drug data sets by patent status.

We sorted the list of all GPI-patent status groups in the merged data set for 2014 by three criteria: (1) total prescription expenditures, (2) number of prescriptions dispensed, and (3) days of therapy provided. The top $500 \mathrm{GPI}$-patent status categories were identified for each of these three criteria. Because some GPI-patent status groups appeared in more than one of these top 500 lists, the combined list of all GPI-patent status groups totaled 627 . There were 268 brand name GPIpatent status groups ${ }^{7}$ (i.e., both brand single source and brand multiple source) and 399 generic GPI-patent status groups. Also, $101 \mathrm{GPI}$-patent status groups in this combined top 500 list were classified as specialty drugs.

The three market baskets (brand name, generic, and specialty drugs) combined accounted for 83.0 percent of all prescription drug expenditures and 82.8 percent of all prescriptions dispensed to those over age 50 in 2014 .

\section{MONITORING RETAIL DRUG PRICES}

The original Rx Watchdog reports were based on market baskets of drugs constructed using data from a Medicare Part D plan provider for 2006 and manufacturer drug price changes measured using WAC data from the Medi-Span Price-Chek PC database. The AARP Public Policy Institute and the University of Minnesota's PRIME Institute collaborated to develop a new retail drug price index known as the Rx Price Watch reports, based on retail-level prescription prices from the Truven Health MarketScan@ Research Databases. This retail price index allows the AARP Public Policy Institute to assess retail prices actually paid by consumers or insurers and to determine whether the rebates and discounts sometimes given to payers are being passed along to consumers.

\section{Retail Data Description}

The Truven Health MarketScan® Research Databases comprise 12 fully integrated claims databases, and contain the largest collection of privately and publicly insured, de-identified patient data in the United States. ${ }^{8}$ The warehouse features an opportunity sample from multiple sources (employers, states, health plans), more than 20 billion patient records, and 196 million covered lives since $1995 .{ }^{9}$ The data used in the $R x$ Price Watch analyses are drawn from the Truven Health MarketScan@ Commercial Claims and Encounters Database (Commercial Database) and the Truven Health MarketScan® Supplemental and Coordination of Benefits Database (Medicare Supplemental Database).

The Truven Health MarketScan® Commercial Database consists of employer- and health plansourced data containing medical and drug data for several million individuals annually. It encompasses employees, their spouses, and dependents covered by employer-sponsored private health insurance. Health care for these individuals is available under a variety of feefor-service (FFS), fully capitated, and partially capitated health plans. These include preferred provider organizations (PPOs) and exclusive provider organizations (EPOs), point of service

7 The current brand name drug market basket originally included 268 widely used brand name drugs. However, fluticasone propionate powder, a corticosteroid used in compounding, had insufficient retail price data in 2017 and was dropped from this analysis. 
(POS) plans, indemnity plans, health maintenance organizations (HMOs), and consumer-directed health plans. ${ }^{10}$

The Truven Health MarketScan® Medicare Supplemental Database is composed of data from retirees with Medicare supplemental insurance sponsored by employers or unions. In 2010, 14 percent of the 46.5 million Medicare beneficiaries received their drug benefits through a retiree coverage plan. ${ }^{11}$ The Truven Health MarketScan $®$ Medicare Supplemental Database includes the Medicare-covered portion of payment, the employer-paid portion, and any patient out-of-pocket expenses. The database provides detailed cost and use data for health care services performed in both inpatient and outpatient settings.

The retail price data drawn from the Truven Health MarketScan $®$ Commercial Database and Truven Health MarketScan@ Medicare Supplemental Database had to meet several conditions in order to be included in the analysis:

1. Claimant must be age 50 or older

2. Claim must have a value of greater than zero in the following fields:
a. Total payment amount
b. Metric quantity
c. Ingredient cost
d. Days' supply
e. Average wholesale price

3. Payment amount cannot be less than 100 percent of the ingredient cost

4. Claim must come from a noncapitated health plan.

Truven Health Analytics then combined the two databases and provided the AARP Public Policy Institute with data sets that included the monthly median (as well as the 25th and $75^{\text {th }}$ percentile) retail price from January 2005 through December 2017 for all of the drug products in the Rx Price Watch market baskets. We then compiled the monthly median retail prices in spreadsheets designed to track price changes for each of the drug products in the AARP market baskets.

\section{CALCULATING ANNUAL PRICE CHANGES FOR EACH DRUG}

This Rx Price Watch report calculates average retail price changes for drug products in the following ways:

- The annual point-to-point percent change in retail price is the percent change in price for a given month compared with the same month in the previous year (e.g., January $2017 \mathrm{v}$. January 2016, February 2017 v. February 2016).

- The 12-month rolling average percent change in retail price is the average of the point-topoint changes over the preceding 12 months. For example, the average annual retail price changes for 2017 refer to the average of the annual point-to-point price changes for each of the 12 months from January 2017 through December 2017 compared with the same months in 2016.

We calculated average annual price changes for each drug product for each month and year that the drug was on the market from 2006 to 2017. The first step was to calculate the annual point-to-point percent change for each month by comparing the price in a specific month with the same month in the previous year (e.g., January 2017 v. January 2016, February 2017 v. February 2016). The next step was to calculate the average of these annual point-to-point changes for the 12 months in each calendar year. For example, average annual price changes for 2017 refer to the average of the annual point-to-point price for each of the 12 months in 2017. This 12-month rolling average tends to be a more conservative estimate of price changes than the point-to-point method (i.e., a simple percentage change for a single month from the same month in the previous year), and it accounts for seasonal variations in drug manufacturers' pricing policies.

Table A-1 shows how 12-month rolling average price changes are calculated. Suppose, for example, that drug A had the following pattern of price changes in 2017 when compared with the same month in 2016:

10 Danielson, "White Paper."

11 Danielson, "White Paper." 
In this example, the retail price of drug A was 2 percent higher than the price for the same months in the previous year, for the period from January through April 2017. A price hike in May increased the percentage difference to 3 percent for each of the subsequent months in 2017. The 12-month average of these price differences is $(2.0+2.0+2.0+2.0+3.0+3.0+3.0+3.0+3.0+$ $3.0+3.0+3.0) / 12$, or 2.67 percent. $^{12}$

\section{CALCULATING AGGREGATE AVERAGE PRICE CHANGES ACROSS MULTIPLE DRUGS}

To aggregate price changes for multiple drugs, we calculated a weighted average of price changes by weighting each drug's annual price change (calculated from the Truven Health MarketScan $®$ ) Commercial Database and the Truven Health MarketScan® Medicare Supplemental Database, as shown in the hypothetical example in Table A-1) by its share of total 2014 prescription sales within its given market basket (i.e., brand name, generic, specialty, or combined). As an example, Table A-2 shows that the sample from which drug A was drawn has 10 drugs (we chose this small sample size to simplify this illustrative example). The second column of Table A-2 gives the average annual price change for each of these drugs, denoted as drugs A through J. A straight (or unweighted) average, which adds up individual values and divides by the number of drugs, would result in an average annual price change of 4.76 percent for the drugs in this hypothetical sample. Assuming the hypothetical changes in the dollar cost of therapy for these drugs, shown in the third column, the straight average change in the annual cost of therapy would be $\$ 236.13$.

A straight average, however, does not account for the actual impact of price changes because it does not account for each product's "weight" (or share) within the sample (i.e., it gives equal weight to price changes of both commonly used drugs and drugs that are used less frequently). As a result, it does not accurately capture the average impact

Table A-1

Average Annual Percent Change in Price for Hypothetical Prescription Drug A, 2017

\begin{tabular}{|c|c|c|c|c|c|c|c|c|c|c|c|c|}
\hline $\begin{array}{l}\text { Jan } 16- \\
\text { Jan } 17\end{array}$ & $\begin{array}{l}\text { Feb 16- } \\
\text { Feb } 17\end{array}$ & $\begin{array}{l}\text { Mar 16- } \\
\text { Mar } 17\end{array}$ & $\begin{array}{l}\text { Apr 16- } \\
\text { Apr } 17\end{array}$ & $\begin{array}{l}\text { May } 16- \\
\text { May } 17\end{array}$ & $\begin{array}{l}\text { Jun 16- } \\
\text { Jun } 17\end{array}$ & $\begin{array}{l}\text { Jul 16- } \\
\text { Jul } 17\end{array}$ & $\begin{array}{l}\text { Aug 16- } \\
\text { Aug } 17\end{array}$ & $\begin{array}{l}\text { Sep 16- } \\
\text { Sep } 17\end{array}$ & $\begin{array}{l}\text { Oct 16- } \\
\text { Oct } 17\end{array}$ & $\begin{array}{l}\text { Nov } 16- \\
\text { Nov } 17\end{array}$ & $\begin{array}{l}\text { Dec } 16- \\
\text { Dec } 17\end{array}$ & Average \\
\hline 2.0 & 2.0 & 2.0 & 2.0 & 3.0 & 3.0 & 3.0 & 3.0 & 3.0 & 3.0 & 3.0 & 3.0 & 2.67 \\
\hline
\end{tabular}

Table A-2

Average Changes in Price and Cost of Therapy for 10 Hypothetical Prescription Drugs, 2017

\begin{tabular}{|c|c|c|c|c|c|}
\hline $\begin{array}{c}\text { Drug } \\
\text { Name }\end{array}$ & $\begin{array}{c}\text { Unweighted } \\
\text { Average Annual } \\
\text { Price Change } \\
\text { (\%) }\end{array}$ & $\begin{array}{c}\text { Unweighted } \\
\text { Average Change } \\
\text { in Cost of Therapy } \\
\text { (\$/year) }\end{array}$ & $\begin{array}{l}\text { Share } \\
\text { of Total } \\
\text { Sales } \\
(\%)\end{array}$ & $\begin{array}{c}\text { Weighted } \\
\text { Average } \\
\text { Annual } \\
\text { Price Change } \\
(\%)\end{array}$ & $\begin{array}{c}\text { Weighted } \\
\text { Average Change in } \\
\text { Cost of Therapy } \\
\text { (\$/year) }\end{array}$ \\
\hline A & $2.67 \%$ & $\$ 623.48$ & $15 \%$ & $0.40 \%$ & $\$ 93.52$ \\
\hline B & $10.00 \%$ & $\$ 108.68$ & $14 \%$ & $1.40 \%$ & $\$ 15.22$ \\
\hline C & $2.67 \%$ & $\$ 433.68$ & $7 \%$ & $0.19 \%$ & $\$ 30.36$ \\
\hline D & $8.00 \%$ & $\$ 54.08$ & $10 \%$ & $0.80 \%$ & $\$ 5.41$ \\
\hline E & $1.50 \%$ & $\$ 162.76$ & $5 \%$ & $0.08 \%$ & $\$ 8.14$ \\
\hline$F$ & $4.33 \%$ & $\$ 54.08$ & $14 \%$ & $0.61 \%$ & $\$ 7.57$ \\
\hline G & $6.40 \%$ & $\$ 216.84$ & $2 \%$ & $0.13 \%$ & $\$ 4.34$ \\
\hline $\mathrm{H}$ & $3.25 \%$ & $\$ 433.68$ & $18 \%$ & $0.59 \%$ & $\$ 78.06$ \\
\hline I & $7.80 \%$ & $\$ 27.04$ & $13 \%$ & $1.01 \%$ & $\$ 3.52$ \\
\hline$J$ & $1.00 \%$ & $\$ 247.00$ & $2 \%$ & $0.02 \%$ & $\$ 4.94$ \\
\hline TOTAL & $4.76 \%$ & $\$ 236.13$ & $100 \%$ & $5.22 \%$ & $\$ 251.07$ \\
\hline
\end{tabular}

12 If the drug was introduced to the market in July of the previous year, then the price change for the given year is averaged using only the six months that the product was on the market in the previous year (i.e., July through December). 
of price changes in the marketplace. In Table A-2, drugs with low price increases in percentage terms (drugs E and J) account for a small share (7 percent) of total 2014 sales for the specific group of drugs analyzed. By contrast, drugs with the highest percentage changes (drugs $\mathrm{B}, \mathrm{D}$, and I) account for a much larger share (37 percent) of sales. To reflect the relative importance of each drug's price change in the market basket of products, we weighted each annual price change by the drug's share of total 2014 sales. In this simple example, the weighted average price increase in 2017 is the sum of

(Unweighted average price change for drug A $\times$ drug A's share of total sales) +

(Unweighted average price change for drug $B \times$ drug B's share of total sales) +

(Unweighted average price change for drug $\mathrm{C} \times$ drug C's share of total sales) +

$\ldots+$ (Unweighted average price change for drug J $\times$ drug J's share of total sales),

or

$(2.67 \times 0.15)+(10.0 \times 0.14)+(2.67 \times 0.07)+\ldots+(1.0$ $\times 0.02$ ).

The results of this calculation are in the fifth column of Table A-2, which shows that the weighted annual average price change for the drugs is 5.22 percent, or approximately one-half a percentage point higher than the unweighted average of 4.76 percent. The weighted dollar change in the annual cost of therapy would be \$251.07, compared with the unweighted average dollar change of $\$ 236.13$.

\section{CALCULATING AVERAGE PRICE CHANGES ACROSS MULTIPLE DRUGS FOR YEARS BEFORE 2014}

The process for aggregating price changes for multiple drugs pre-2014 is similar to that for 2014 . Average price changes for 2006 through 2013 were derived by first calculating the rolling average annual price change for each drug (as shown in Table A-1), then weighting each drug's price change by its share of total sales in the sample. The weights used for all years in this study are from 2014 sales from the Medicare Part D plans of a Medicare Part D plan provider, including the AARP plans, as well as from the Truven
Health MarketScan® Commercial Database, and the Truven Health MarketScan® Medicare Supplemental Database. The 2014 weights keep the market basket constant over time so that the change in prices would be a function of price changes alone and not a function of changes in market basket utilization or mix.

However, some drugs that were in the 2014 sample were not on the market in all earlier years. We dropped these drug products from the analysis in the month before they entered the market and for all previous months, and recalculated the weights of the products present in the market prior to 2014 to reflect their relative share of the total sales as adjusted to reflect only drugs on the market during that period.

For example, suppose that drugs I and J in Table A-2 were not on the market in 2011. Furthermore, assume that total drug spending in 2014 was $\$ 100,000$. To capture the loss of drugs I and J from the analysis for 2011, the weights are redistributed across the drugs that remain in the analysis (drugs A through $\mathrm{H}$ ); the new weights are still based on their 2014 sales but as a share of total sales for the smaller number of drugs in the analysis for the year. In this example, the total 2014 sales of drugs on the market in 2011 would be $\$ 85,000$ without drugs I and J. Drug A's $\$ 15,000$ in sales, which represented 15 percent of sales for all 10 drugs, rises to 18 percent of sales when I and J are excluded. This weight, along with the analogous weights for drugs B through $\mathrm{H}$, was used to derive the weighted average price change for 2011 (see Table A-3).

Weighting the previous years' price changes by 2014 sales potentially creates a bias relative to using each specific year's sales as the basis for assigning weights for that year. Using 2014 sales gives more weight to drugs that, relative to other drugs, had high rates of sales growth in 2014 or earlier years compared with the year analyzed. In general, however, newer drugs initially have higher rates of sales growth, but relatively lower rates of price growth, than do older drugs. This pattern occurs both because newer drugs may have been introduced at higher prices and because price increases for brand name drugs tend to accelerate in rate and amount closer to the end of a product's effective patent life. 
Recalculating Weights When Prescription Drugs Drop out of the Sample

\begin{tabular}{|c|c|c|c|c|}
\hline \multirow[b]{2}{*}{ Drug Name } & \multicolumn{2}{|c|}{2014 Weights } & \multicolumn{2}{|c|}{2011 Weights } \\
\hline & $\begin{array}{c}\text { Share of } \\
2014 \text { Sales } \\
(\%)\end{array}$ & $\begin{array}{c}\text { Value of } \\
2014 \text { Sales } \\
\text { (\$) }\end{array}$ & $\begin{array}{l}2014 \text { Sales of Drugs } \\
\text { on Market in } 2011 \\
\text { (\$) }\end{array}$ & $\begin{array}{c}2014 \text { Share of Drugs } \\
\text { on Market in } 2011 \\
(\%)\end{array}$ \\
\hline A & $15 \%$ & $\$ 15,000$ & $\$ 15,000$ & $18 \%$ \\
\hline B & $14 \%$ & $\$ 14,000$ & $\$ 14,000$ & $16 \%$ \\
\hline C & $7 \%$ & $\$ 7,000$ & $\$ 7,000$ & $8 \%$ \\
\hline D & $10 \%$ & $\$ 10,000$ & $\$ 10,000$ & $12 \%$ \\
\hline$E$ & $5 \%$ & $\$ 5,000$ & $\$ 5,000$ & $6 \%$ \\
\hline $\mathbf{F}$ & $14 \%$ & $\$ 14,000$ & $\$ 14,000$ & $16 \%$ \\
\hline G & $2 \%$ & $\$ 2,000$ & $\$ 2,000$ & $2 \%$ \\
\hline H & $18 \%$ & $\$ 18,000$ & $\$ 18,000$ & $21 \%$ \\
\hline I & $13 \%$ & $\$ 13,000$ & - & - \\
\hline$J$ & $2 \%$ & $\$ 2,000$ & - & - \\
\hline TOTAL & $100 \%$ & $\$ 100,000$ & $\$ 85,000$ & $100 \%$ \\
\hline
\end{tabular}

\section{CALCULATING ANNUAL COST OF THERAPY FOR A DRUG PRODUCT}

To assess the impact of price changes on dollars spent, we calculated an annual cost of therapy for each drug product. This annual cost of therapy analysis excludes drug products in the market basket that are used primarily for treatment of acute conditions or that are typically taken for a limited period of time. The amount of a drug that an average adult would take on a daily basis was determined using the "usual daily dose" reported in the Medi-Span Price Rx Pro® database.

When this information was not available from Medi-Span, we used dosing information in the FDA-approved labeling for the drug product. The weighted average annual cost of therapy was also calculated using the 2014 sales volumes to weight the annual cost of each drug product to produce the aggregate annual cost of therapy across all drug products in the study's market basket.

\section{DEFINING MANUFACTURER}

We defined a drug manufacturer as the firm marketing the drug product under its corporate name in 2014. If a listed manufacturer is a division of another firm, we defined its drugs as marketed by the parent firm. This includes cases in which the firm marketing a drug product may have changed over time due to mergers and acquisitions, divestitures of specific drug products, or for other reasons. The analysis of drug manufacturers reported separately on manufacturers with at least two drug products (at the NDC level) among the most widely used drugs.

\section{DEFINING THERAPEUTIC CATEGORY}

Drug products can be classified by the therapeutic purpose for which they are used. If a drug has multiple uses, the most common indication typically becomes the classifier. To group drug products in this study into similar therapeutic categories, we used Medi-Span's therapeutic coding scheme, known as the GPI code.

The therapeutic categories used in this study use an intermediate GPI-level code that specifies the groupings of similar chemical entities such as "Proton Pump Inhibitors." A brand name therapeutic category may include drug products that are brand single source or brand multiple source. 


\section{Appendix B \\ Therapeutic Category \\ Acronyms}

\begin{tabular}{|c|c|}
\hline Therapeutic Category & Definition \\
\hline CNS Agent, Misc & CNS - Central Nervous System \\
\hline DMARD & DMARD - Disease-Modifying Anti-Rheumatic Drugs \\
\hline JAK Inhibitors & JAK - Janus Kinase \\
\hline Antiretrovirals - NNRTI & NNRTI - Non-Nucleoside Reverse Transcriptase Inhibitors \\
\hline
\end{tabular}


Research Report 2019-16, June 2019 (c) AARP PUBLIC POLICY INSTITUTE 601 E Street, NW

Washington DC 20049

Follow us on Twitter @AARPpolicy on facebook.com/AARPpolicy www.aarp.org/ppi

For more reports from the Public Policy Institute, visit http://www.aarp.org/ppi/.

https://doi.org/10.26419/ppi.00073.001 